\title{
Point-of-care testing devices for heart failure analyzing blood and saliva samples
}

\author{
Evanthia E. Tripoliti, Member, IEEE, Penelope Ioannidou, Petros Toumpaniaris, Aidonis Rammos, Dominique \\ Pacitto, Jean-Christophe Lourme, Yorgos Goletsis, Member, IEEE, Katerina K. Naka, Abdelhamid Errachid, \\ Dimitrios I. Fotiadis, Senior Member, IEEE
}

\begin{abstract}
Heart failure (HF) is the most rapidly growing cardiovascular condition with an estimated prevalence of $>37.7$ million individuals globally. HF is associated with increased mortality and morbidity and confers a substantial burden, in terms of cost and quality of life, for the individuals and the healthcare systems, highlighting thus the need for early and accurate diagnosis of $\mathbf{H F}$.

The accuracy of HF diagnosis, severity estimation and prediction of adverse events has been improved by the utilization of blood tests measuring biomarkers. The contribution of biomarkers for HF management is intensified by the fact that they can be measured in short time at the point-of-care. This is allowed by the development of portable analytical devices, commonly known as Point-of-Care Testing (POCT) devices, exploiting the advancements in the area of microfluidics and nanotechnology.

The aim of this review paper is to present a review of POCT devices used for the measurement of biomarkers facilitating decision making when managing $\mathrm{HF}$ patients. The devices are either commercially available or in the form of prototypes under development. Both, blood and saliva samples are considered. The challenges concerning the implementation of POCT devices and the barriers for their adoption in clinical practice are discussed.
\end{abstract}

\section{INTRODUCTION}

Heart failure (HF) is an important cardiovascular disease and a cause of death of 17.7 million people yearly, a number that corresponds to $31 \%$ of all global deaths according to a report provided by the World Health Organization (WHO) [1]. The HF demonstrates high prevalence rates (approximately $1-2 \%$ of the adult population). This figure exceeds $10 \%$ among people $>70$ years old. The lifetime risk of $\mathrm{HF}$ at age $>55$ years is $33 \%$ for men and $28 \%$ for women [2,3]. The increased healthcare costs, that have been associated with HF, are due to recurrent cardiovascular and non-cardiovascular events and repeated hospitalizations that occur during the course of the HF disease. The economic burden that is posed by HF, in combination with the demographic shift towards an ageing population with high prevalence of chronic diseases, make HF a significant threat for society, necessitating the early diagnosis of the disease and consequently the application of the appropriate interventions, as well as monitoring of the disease [2].

The measurement of biochemical markers, indicative for initial evaluation of $\mathrm{HF}$, risk stratification, screening and therapy monitoring of $\mathrm{HF}$ patients, contribute towards this direction. A short presentation of biomarkers that have been emerged in HF literature and are either used in clinical practice or being under study is provided in Section II. The measurement of biomarkers' concentration is achieved using non-invasive or invasive techniques allowing either the detection of the same biomarker at a different time or the detection of different biomarkers at the same time [4]. The analysis of samples is mainly performed in centralized laboratory settings where bench-top analyzers, operated by trained personnel, are utilized and blood is mainly used. The clinical laboratory testing pathway includes steps such us sample transport, processing of specimen (e.g. clotting, centrifugation etc.) and aliquoting processes, which increase the turnaround time of the results and consequently the need for physicians to remember a case after results come from the laboratory, the time for the delivery of diagnosis and the provision of treatment and the complexity of the workflow.

The need to: (i) make healthcare more patient-centered, (ii) reduce hospital admissions, (iii) decrease hospital length of stay, (iv) improve access to and quality of care, (v) increase provider and patient satisfaction, (vi) take care of a larger population of elderly patients with multiple chronic conditions, (vii) optimize clinical efficiency and staff time, in combination with the laboratory staff shortages, the push toward decentralized laboratory testing, and the rapid evolution of microfluidics and lab-on-a-chip technologies, are the factors driving the development and the evolution of the Point-of-Care Testing (POCT) devices which collect the sample and perform the analysis in the same location.

POCT can be defined as any biochemical diagnostic test that takes place outside the central laboratory and near to the patient or at the patient's bedside. More specifically, according to Sheppard et al. [5], "POCT refers to pathology testing performed in a clinical setting at the time of patient consultation, generating a test result that contributes to an immediate informed clinical decision being made and acted upon for patient care". Beside fast turnaround time facilitating decision making of medical staff, POCT offers several other advantages not only for the patient but also for the healthcare centers and healthcare systems. Those advantages contribute significantly to the adoption of POCT in a variety of fields including glucose measurements, pregnancy testing, screening of infectious diseases, blood parameters measurements, as well as the detection of cardiovascular diseases.

This study presents a review of POCT devices either available in the market or in the form of prototypes, as well as the challenges associated with its implementation and the barriers for their adoption in clinical practice. The systematic literature review was based on sources like: i) PubMed, ii) Scopus, iii) Science Direct, iv) Google Scholar and v) Web of Science (WoS) using as keywords the phrases "point-of-care 
testing", "near patient testing", "bedside testing", each in conjunction with heart failure. The studies reported in the literature were selected based on the following criteria: i) focus on heart failure, ii) concern the analysis of blood or saliva samples, iii) are written in English, iv) are published from 2000 (inclusive) until present and v) cover different geographical locations. Studies not fulfilling more than one of the above mentioned criteria were excluded. A diagram of the search strategy that was followed for each one of the abovementioned sources is presented in Appendix 1.

The rest of the paper is organized as follows. In Section II biomarkers related to HF are presented. Section III provides information regarding the criteria the POCT devices should fulfil and the taxonomy of POCT devices based on different aspects (e.g. size, area of use, underlying detection principle, analyzer etc.). Section IV describes the available POCT devices utilized in HF disease management. Section IV is divided in two parts: the first one describes POCT devices analyzing blood samples and the second part presents POCT devices performing analysis on saliva samples. Section V reports challenges concerning the implementation of POCT devices and the barriers for their adoption in clinical practice. Finally, conclusions and future trends are presented in Section VI.

\section{ROLE OF BIOMARKERS IN HEART FAILURE}

The understanding of the role of biomarkers for the prevention, assessment, and management of HF has gained the interest of HF community. There is growing body of consistent literature supporting the use of biomarkers in the assessment of the risk for incident of HF, the diagnosis, the prognosis of adverse events, the prevention and the guidance of HF treatment [6-8]. The biomarkers can be grouped according to their pathophysiological mechanism to the following categories [6]: i) neurohormones, ii) markers for extracellular matrix remodeling, iii) inflammatory mediators and markers of oxidative stress, iv) myocyte injury and myocyte stress, v) other biomarkers. Biomarkers belonging to the above mentioned categories are: B-type natriuretic peptide (BNP), N-terminal proBNP (NT-proBNP), C-reactive protein (CRP), cardiac troponin I or T(cTn-I or cTn-T), interleukin (IL-1, IL-6, IL-10, IL-33), tumor necrosis factor alpha (TNF- $\alpha$ ) and receptors, growth differentiation factor 15 (GDF-15), gelatinaseassociated lipocain -3 (GAL-3), soluble suppressor of tumorgenicity 2 (sST2), ST2 membrane-bound receptor (ST2L), pentraxin 3 (PTX3), procollagen I intact $\mathrm{N}$-terminal (PINP), procollagen I C-terminal propeptide (PICP), type III procollagen peptide (PIIINP), insulin-like growth factor-1 (IGF-1), insulin growth factor-bind protein 7 (IGF-7), Gprotein coupled receptor kinase-2 (GRK-2), matrix metalloproteinase (MMP), tissue inhibitor of matrix metalloproteinase (TIMP), carboxy-terminal telopeptide of collagen type I (CITP), myotrophin, leptin, adiponectin, ghrelin, apelin, cystatin-C. Furthermore, standard laboratory markers such as sodium, blood urea nitrogen, serum creatinine, hemoglobin, leukocyte count, total lymphocyte count, serum albumin, total bilirubin, uric acid and red blood cell distribution width are measured.

Monitoring the concentration of the aforementioned biomarkers in the blood can provide significant clinical information about the management of HF. The role of BNP and NT-proBNP testing is already included in the task force of the European Society of Cardiology and American Heart Association guidelines for confirming or refusing the diagnosis of HF, as well as for the stratification of long-term risk profiles. A summary of the recommendations/suggestions for the utilization of the biomarkers reported in a scientific statement from the American Heart Association (AHA) [6] and in the guidelines of the National Academy of Clinical Biochemistry Laboratory (NACBL) [7] is provided in Table I.

The biomarkers that are utilized in clinical practice are BNP, NT-proBNP, CRP, cTn-I and cTn-T. These biomarkers are measured either in laboratory settings or using POCT devices by analyzing blood samples. However, recently the utilization of saliva as a liquid biopsy has gained the attraction for the detection of a broad range of oral and systemic diseases [9]. Saliva is a complex fluid that can act as a "mirror of body health" since it includes informative proteins and peptides that can be measured in a fast, easy, non-invasive and low cost way. Salivary diagnostics, exploiting the fact that saliva is easy to store and ship, does not clot and can reflect the current pathophysiological state of an individual, emerged recently and a large number of studies are presented in the literature demonstrating the relation between the concentrations of specific saliva biomarkers with the detection of cardiovascular diseases $[10,11]$. More specifically, soluble vascularization cellular adhesion molecule-1, troponin I, growth related protein-alpha, epithelial cell-derived neutrophil-activating peptide 78, creatine kinase-myoglobin, CRP, MMP-9, myeloperoxidase (MPO), myoglobin, TNF- $\alpha$, soluble CD40 ligand, IL-1 $\beta$, IL-6, soluble intracellular adhesion molecule, adiponectin, leukotriene B4, prostaglandin E2, NT-proBNP, cTn-I, BNP, monocyte chemoattractant protein-1, unstimulated whole saliva, and cortisol has been studied [10-17]. Focusing on HF, NT-proBNP, TNF- $\alpha$ and cortisol have demonstrated diagnostic and prognostic capacity $[18,19]$.

In order to be used in clinical practice the biomarkers should fulfil the following criteria: i) allow accurate and reproducible measurements, ii) can be measured in short time, iii) can be measured in reasonable cost, iv) provide validated clinical information not already available, v) their performance is superior to other available tests, vi) can facilitate clinical decision making and enhance the provided clinical care, and vii) the assay should be easy to perform and analyze [4].

\section{POINT-OF-CARE TESTING DEVICES}

\section{A. Application of POCT devices}

POCT devices make use of miniaturized versions of laboratory technologies, allowing many clinical pathology 
based tests to be performed in a range of settings and in many fields of medicine [20].

The use of POCT devices has advantages affecting not only the patient but also the POCT operator, the medical practitioner, the health service, the healthcare systems and society. The main advantage of POCT is the short time of generation of results and thus the early initiation of treatment. Furthermore, the collection of samples is less stressful and almost noninvasive, allowing the individual to observe the whole process increase the levels of his/her self-motivation, self-screening and adherence to medication. The earlier screening of the disease and provision of personalized treatment results to improved patient care, earlier discharge from the hospitals and to the decrease of patient visits $[5,20]$. The above mentioned advantages contribute towards better monitoring and management of epidemics, reducing waiting time targets and lowering the costs for the healthcare insurances and the healthcare systems. The POCT devices simplify and make less expensive the management of samples, minimize the risk of sample contamination and allow the incorporation of the less specialized personnel to the test performance. Finally, due to their portability, POCT devices provide access to advanced medical technologies in the developing world or remote locations, ease the installation of mobile field hospitals and are available to community events such as health screening days, health promotion activities and disease awareness programs fostering community engagement, capacity building and resilience $[5,20]$.

\section{B. Required features of POCT devices}

POCT devices should follow the so called ASSURED guidelines defined by the World Health Organization (WHO) [21], an acronym extracted by the words Affordable, Sensitive, Specific, User friendly, Rapid and Robust, Equipment free, Delivered. More specifically, each POCT device should address the needs of the user in a clinically and cost-effective manner (Affordable by those at risk of infection), provide the results in short turnaround time and there is no need for refrigerated storage (Rapid and robust), while the delivered results contain minimal false negatives (Sensitive and minimal false positives - Specific). Additionally, POCT devices should be easily used by a spectrum of users, lay persons to highly trained, and the test requires a minimum number of steps (User friendly) in order to be performed. Finally, POCT devices should not require complex equipment (Equipment free) and they are accessible to end users (Delivered). The ASSURED criteria should be achieved, as far as possible, by the nine key design elements of POCT devices: 1) operator interface, 2) sample delivery device, 3) bar code identification system, 4) reagent storage and availability, 5) sensors to detect the measurement reaction, 6) control and communication systems, 7) data management and storage, 8) manufacturing requirements, 9) reaction cell [22].

\section{Taxonomy of POCT devices}

The large number of POCT devices currently available on the market does not allow an analytical presentation of them. However, an overview of the different types of POCT devices and a taxonomy of them according to: i) size and portability, ii) complexity/risk of harm, iii) type of the provided results, iv) type of specimen under testing, v) analytes, vi) test format, vii) reagent, viii) detection process, ix) data transfer technology is presented below [5].

\section{Size and portability}

POCT devices come in various sizes and shapes, from small portable systems to heavy bench-top automated analyzers which are barely smaller than central mainframes. Most of the POCT analysis can be performed by the patient himself and consists of small handheld apparatus. The most representative of these, is the glucose-meter which is widely used by diabetic patients to manage their glycaemia. Bench top monitors are mainly located in primary care centers, clinics or hospitals. They host more complex technologies that allow more accurate results to be delivered.

\section{E. Complexity/risk of harm}

The POCT devices can be either classified as "low", "moderate" or "high" complexity based on Clinical Laboratory Improvement Amendments (CLIA) Act 1988 or classified as In-Vitro Device of class I (IVD-class I) to IVD-class IV based on the risk posed to the health of the general public or the individual [5].

\section{F. Type of the provided results}

The results provided by the POCT devices can be: i) quantitative, a number in a specified unit of measurement, ii) qualitative, an indication for the presence or not of the disease, iii) semi-quantitative where a range of concentrations within which the results lay is provided [5].

\section{G. Type of specimen under testing}

Specimen types that can be measured by a POCT device include blood, urine, saliva, semen, sweat of breath, genital, nasal or throat swabs and faeces with the first two being the most common [5].

\section{H. Analytes, Reagents and detection process}

A POCT device can detect a large variety of target analytes (e.g. small molecules, enzymes, proteins, cells, infectious agents, drugs of abuse, cardiovascular biomarkers etc.). The detection process of analytes consists of one or two main steps: i) recognition of the analytes to be tested, ii) detection of the resultant signal. Target analytes interact with one or more reagents in order to be revealed. Reagents can be classified to chemo-sensors and bio-sensors. In the first case, a chemical indicator or a binding molecule is used in order a chemical reaction to take place, while in the second case, an antibody or enzyme is used in order analytes to be recognized. 
In systems where higher precision or quantification of analytes is needed, a detection process follows the reaction step. The detection process can be performed using either photometric-optical or electrochemical methods. Spectrophotometry, reflectometry, immune-chromatography, surface plasmon resonance, turbidimetry are common optical methods. Electrochemical techniques include potentiometry, amperometry and impedancemetry. Optical methods are based on the quantitative measurement of the reflection or transmission properties of a material or light as a function of wavelength. Electrochemical methods are based on the measurement of the electrical energy produced due to the movement of electrons from one element to another. Field effect transistor based immune-sensors are also an efficient solution for the quantification of the bio interaction of target analytes and antibodies capturing of antigen into an electric signal. The main advantages of these transducers are high sensitivity and selectivity, label-free detection, real-time response, cost-effective fabrication, ease of miniaturization and integration [23].

\section{Testing format}

The three main testing formats employed in POCT devices are: i) single-use, qualitative or semi-qualitative testing strips or cups, ii) single-use testing strips or test receptacles with a reading (or monitoring) device and iii) multi-use quantitative testing cartridges with a larger bench-top reading or monitoring device. Characteristic examples of the first category of testing format are dipsticks and lateral flow immune assay (LFIA) test strips. Urine dipsticks, consisting of a series of reagent pads, is an indicative example. Strips based on LFIA can be further grouped to competitive and sandwich. The main difference of these two LFIA formats concern the correlation of the response with the amount of analyte in the sample. LFIA strips consist mainly of sample application area, conjugate release pad, detection zone and absorbent pad. The second type of testing format (single-use testing strips or test receptacles with a reading or monitoring device) includes cartridge, cassette, cuvette and rotor containers. A reading device is required for monitoring the reaction and measuring-quantifying the signal in short turnaround time.

\section{J. Systems of integration of detection process}

Systems integrating detection process components are: i) paper-based, ii) lab on a chip (LOC), iii) bead-based, iv) nucleic acid. Paper-based systems are in general easy to use and lowcost. Home pregnancy tests, glucose detectors and lateral flow immunoassays for infectious diseases are the most prevalent tests based on this technology. In general, no containers are required to collect samples and very few amount is drawn from the body (less than one micro liter of capillary blood for example) by means of adapted tools (swabs, needles etc.). The most widespread systems that host paper-based technologies are dipsticks and strips. Results are mainly qualitative and consist of a color or mark which is interpreted by the test operator by means of a reference table. This technology suffered, for a long time, from poor accuracy and reproducibility mainly due to uncertainties engendered by the capillary spread of the sample toward the sensing sites, which cannot be precisely controlled, and due to degradation or contamination of the samples during the flow process. To address these issues, different solutions have been developed. Reader systems, such as CCD camera colorimeters, can significantly improve the interpretation of the test and provide a mean to quantify its results. The recent advances and state of the art in paper-based analytical devices is presented in [24]. Control of the sample and reagent flow can also be done with the help of microfluidics [25-27]. Detection of multiple analytes is also made easier and more precise with this technology. The use of fluorophore, QDot or magnetic particles as reporter particles, are typical efficient strategies to enhance the detection sensitivity [28]. Vashist et al. [29] also mentions, among others, the use of acoustic fields and the application of thermal contrasting techniques.

Progress in miniaturization has led to the possibility of integrating all the components that are necessary to perform a complete analysis on a single chip. The size of this chip is generally few square millimeters. Any sort of detection or sample handling technologies can be implemented as long as they are small enough to fit on the chip. Microfluidics is a prominent example [25-27]. LOC platforms take a great advantage of it and can reproduce all sorts of flow control operations that can be done in a central laboratory, with very much fewer amount of sample [30].

Systems which do not use LOC or paper based systems are mostly large bench-top equipment. They are often capable of detecting more than one analytes at once and the technologies that are used are similar to those found in central laboratories and have benefited from advanced miniaturization and automation techniques. Bead-based and nucleic acid systems are representative examples. Beads coated with antibodies, of size in range of 10 to 100 micro meters, are used to capture targets markers. After this step, different strategies can be applied to detect the bound beads. Underlying principles behind them are: i) the analysis of physical properties of beads like color, size or shape and ii) the detection of labelled reporter particles that bound to the bead-bound antigen. Array configuration of microbeads are also used for multiplexed analysis.

Point of care for nucleic acid testing are processed on large bench-top equipment that host highly complex DNA handling technologies. As pointed out by Hart et al. [31], their sensitivity is 3 to 4 times higher than immunoassays. In comparison to other POCT systems, the procedure for the full analysis requires much more steps as DNA needs to be extracted and purified, and nucleic acids have to be isolated and duplicated by enzymatic or isothermal amplification. There is large number of different reagents and washing liquids and microfluidics is widely employed to handle the complexity of the flow controls 
of them. All these aspects imply that the average turnaround time is much longer (almost $90 \mathrm{~min}$ ).

\section{K. Data transfer technology}

Connectivity is a major feature of POCT equipment and it is considered as one of the major drivers of the POCT market as it greatly facilitates: i) the quality control, ii) the identification of testing personnel, iii) the management of the patient medical record, iv) the access to the results from all staff on the care team through a healthcare network, v) timely and optimal care decisions, vi) the inclusion of POCT data in analytics needed for the risk stratification and population health statistics, vii) the timely diagnosis and treatment, viii) the automatic billing. Moreover, sharing of POCT results with the laboratory and hospital information system (LIS, HIS) addresses data loss concerns which could occur once the patient is no longer at the testing location or when the internal memory of the POCT device is fully loaded and it should be cleaned in order to host new results. Additionally, data transfer allows the analysis of measurements in distant calculation servers or through dedicated mobile applications developed in order to support patients' management. The mobile application can either directly communicate with the POCT device or retrieve the necessary information (biomarker values) form LIS, and the electronic health record more specifically, once they have been transferred there from the POCT device. The interconnectivity approaches mentioned above presuppose the development of a computer interface or a middleware, ongoing maintenance, as well as a proprietary data management. Furthermore, as applicable to any lab test, correct display of results has to be verified. The possibility for the information technology (IT) staff not to understand the POCT and therefore try to consolidate all methods into one general test display should be diminished. The challenge is how to best integrate POCT data [32].

Thanks to the POCT Connectivity Standard (POCT1-A), the data management is standardized which means that no specific manufacturer constraints exists in terms of connectivity. Many POCT devices offer cabled, bidirectional interfaces with the LIS such as RS232 or USB to PC communication. Some of them can even send and receive information wirelessly, the most common protocol being Bluetooth. Another solution is barcode scanner [33]. It reduces identification mistakes from manual entry drastically. Almost all of the large handheld and bench top devices are equipped with this system. It allows the scanning of containers (type, lot, expiration date), patients' and users' identification codes, QC data (QC material, lot, basis, expiration date, target values, etc.) and any other alphanumeric code. Thus, barcode scanners make the entry of information easier, compared to manual typing. They integrate a decoder which is preprogrammed to read code types such as UPC-, EAN-, or code 128. Failure of scanners must be avoided at all cost as it forces the staff to type data manually which increases errors. That is why the medical staff should be trained to use them properly, since training lead to an optimal scanner performance and a non-use of manual entry.

\section{POINT-OF-CARE TESTING DEVICES FOR HEART FAILURE}

\section{A. Point-of-care testing devices analyzing blood samples}

POCT for detection of biomarkers in cardiovascular diseases exists since 25 years [34]. A sandwich immunoassay technique was first implemented providing qualitative results. The separation of plasma from blood is a necessary pre-processing step in order capturing of biomarkers by the antibodies to be achieved. A volume of 100 micro liters of venous blood is usually drawn from the patient for the analysis to be performed. The procedure followed in paper based tests has known noticeable improvements due to the adjunction of an optical reader or microfluidics capabilities. The size of POCT devices dedicated to the detection of cardiovascular biomarkers varies from large handheld to benchtop system with the latter having greater sensitivity. For the majority of the POCT devices, the turnaround time is about 20 minutes.

As mentioned in Section II among the most common validated biomarkers for HF are cardiac troponins (cTnI and cTnT) and NT-proBNP. The level of cardiac troponins in the blood provide information regarding the damage of the myocardium, while NT-proBNP is useful for risk determination and screening of patients presenting symptoms of acute $\mathrm{HF}$ [34]. Although POCT utilization for the measurement of troponin is available for nearly 20 years and the POCT for troponin comply with the recommended $1 \mathrm{~h}$ procedure for the rule-in and rule-out of the patients, the high sensitivity troponin assays used in the central laboratory settings prohibit their adoption. According to $\mathrm{Wu}$ [34], POCT devices for troponin are not able to detect the normal level of troponin in healthy patients. There are very few commercial devices with performances that are almost equivalent to those of high sensitive and precise analyzers. Contrary to troponin, detection of natriuretic peptides can be assessed in POCT with the same efficacy as with central laboratory platforms. Measurement of these biomarkers has numerous advantages for healthcare management in emergency departments (time and cost savings, screening efficiency etc.) as demonstrated by Muller et al. [34]. Shephard et al. [5] concludes that central testing will undoubtedly be abandoned for this application.

Besides cardiac troponins and NT-proBNP and BNP, nowadays there are both qualitative and quantitative commercial POCT devices for myoglobin, creatine kinasemuscle/brain (CK-MB), and other markers [36-47]. A short comparison of the POCT devices that are available in the market and provide quantitative measurements of cardiovascular biomarkers by analyzing blood samples is presented in Table II and Table III covering different aspects of the POCT devices. The performance measures of these devices (measurable range, limit of detection, limit of quantification, cut-off points and/or reference range) for each one of the detected biomarkers in the blood are presented in Table IV. As 
far as established clinical threshold values of those biomarkers are concerned, according to the authors knowledge they are reported only for natriuretic peptides as follows: (i) Normal Range: $<300$, (ii) Age $<50$ years: NT-proBNP $>450 \mathrm{pg} / \mathrm{mL}-$ HF likely, (iii) Age 50-75 years: NT-proBNP $>900 \mathrm{pg} / \mathrm{mL}-\mathrm{HF}$ likely, (iv) Age $>75$ years: NT-proBNP $>1800 \mathrm{pg} / \mathrm{mL}-\mathrm{HF}$ likely [2].

\section{B. Point-of-care testing devices analyzing saliva samples}

The identification and detection of salivary biomarkers for the determination of the risk, the severity of a disease, as well as the response to treatment gain the interest of researchers and convert salivary diagnostics to an emerging field [11]. This is due to the fact that $[48,49]$ : (i) saliva collection process is noninvasive causing minimal discomfort and anxiety and thus improves patient compliance for testing, (ii) a small volume of sample is needed, (iii) the use and exposure to chemical reagents is limited, (iv) the device utilized for the analysis is disposable and low-cost, (v) the processing time is very rapid and the process is performed automatically, (vi) the saliva is a complex fluid that can act as a diagnostic medium for a range of oral and systemic diseases such as diabetes, periodontal diseases, caries, oral cancer, Sjogren syndrome, oral squamous mucous fibrosis, hepatitis, human papilloma virus, chronic obstructive pulmonary disease and acute myocardial infarction [9].

The saliva fluid consists of various enzymes, nuclei acids, electrolytes, proteins, cytokines, antibodies, antimicrobial constituents and hormones the analysis of which reflect the body health or disease. Among the major salivary diagnostic toolboxes are proteomes, metabolomes, genomes, microbiomes and immunologic. A presentation of the salivary diagnostic toolboxes is provided in $[9,50]$.

The potential of salivary biomarkers in combination with the advantages of POCT lead to the development of salivary biomarker-based POC platforms. The measurement of molecular level of biomarkers in the form of proteins, DNA, mRNA and electrolytes is based on the application of microfabrication techniques. A representative example is microfluidics or micro/nanoelectromechanical systems (MEMS/NEMS). The current emerging technologies (biosensors, fluorescent biosensors-FRET biosensor, biological microelectromechanical systems, microfluidics-paper based technology, electric field induced release and measurement EFIRM, smartphone based biosensors) facilitate the application of point-of-care diagnostics for "lab-on-a-chip" for the simultaneous detection of diseases [9].

Focusing in the area of cardiology, salivary diagnostics play an important role in the risk assessment for cardiovascular diseases in people with insulin resistance and acute myocardial infarction [11]. Salivary biomarkers reported as diagnostic and screening factors for persons with cardiovascular disease include Soluble vascularization cellular adhesion molecule-1 (sVCAM-1), Troponin I (TnI), Growth related protein-alpha (Gro- $\alpha$ ), Epithelial cell-derived neutrophil-activating peptide
78 (ENA-78), CK-MB, CRP, MMP-9, MPO, MYO, TNF- $\alpha$, Soluble CD40 ligand (sCD40L), IL-1 $\beta$, IL-6, Soluble intracellular adhesion molecule (sICAM-1), Adiponectin (Adip), Leukotriene B4 (LTB4), Prostaglandin E2 (PGE2), NTproBNP, cTnI, BNP, Monocyte chemoattractant protein-1 (MCP-1) [50-57]. The relation between salivary biomarkers with specific cardiovascular disease is depicted in Table $\mathrm{V}$.

Some initial research in salivary-based POC platforms for the detection of acute myocardial infraction [17] concluded that complementary to ECG, saliva-based tests within lab-on-a-chip systems may provide a convenient and rapid screening method for cardiac events. The LOC presented in [58] is based on the electronic taste chip (ETC) approach. A sandwich-type immunoassay is used for the measurement of CRP on the ETC LOC system. A detecting antibody is used to visualize the bead-capture analyte. The chemical and immunological reactions take place on and within the interior regions of microspheres positioned in the inverted pyramidal microchamber wells of the microchip, while a microfluidic system controls the flow of a reagents and washes. Detection of the captured analyte is achieved either in fluorescence or colorimetric modes. The optical signal generated on the beads, in both modes, is visualized and captured by a charge-coupled device (CCD) video chip, positioned above the array, along with the use of transfer optics. A LOC multiplexed test is presented in [17] that is based on modifications of the procedures and methods followed in [58] for optimized used in multiplexed Acute Myocardial Infarction (AMI) diagnosis. More specifically, multiplex LOC-based immunoassays for the detection of CRP, IL-1 $\beta$, MYO and MPO are described. According to the study of Floriano et al. [17] the salivary biomarkers that carry important information for the diagnosis of AMI are CRP, sICAM-1, sCD40L, MPO, MMP-9, TNF- $\alpha$, MYO, IL-1 $\beta$, adiponectin, and RANTES. Further, optimizations and improvements lead to the development of a programmable bio-nanochip (P-BNC) system presented in [59]. It includes microelectronic components, microfabrication techniques, and nanotechnology to noninvasively measure multiple cardiovascular biomarkers. The system is characterized as (i) "programmable" since the sensor can be reprogrammed to serve a new application by just inserting biomarker-specific reagents, (ii) "bio" due to the bio-signatures measurement and extraction capability, (iii) "nano" since it is a miniaturized system that can be integrated in to nano-networks and quantum dots, and (iv) "chip" due to the fact that massproduction of the senor elements is allowed. The P-BNC system can measure soluble analytes (through bead microcreators), as well as cell counting, typing, and differentiation (through membrane micro-structures). Finally, in the HEARTEN project [60-62], an integrated electrochemical biosensor was developed for the detection of TNF- $\alpha$ and cortisol biomarkers in real saliva, as a diagnostic medium for HF application [63]. The silicon chips, that constitute the biosensor, is bonded to a standard printed circuit board using wire bonding between the pads on the chip and the printed 
circuit board [64]. A protective epoxy resist is added to protect the wire bonding interconnects. The biosensor includes a metal working microelectrode, a counter electrode based on platinum and Silver/Silver Chloride as a pseudo-reference electrode. Electrochemical impedance spectroscopy was used for the electrochemical characterization of the individual cytokines [65]. The inflammatory response of recombinant human proteins TNF- $\alpha$ and cortisol were measured in Phosphate buffered saline (PBS).

\section{CHALLENGES - BARRIERS RELATED TO POCT SYSTEMS}

POCT systems moved clinical diagnostic testing closer to the patient and allowed measurement of biomarkers to be performed outside the traditional central laboratory. POCT systems reduced turnaround time of laboratory analysis of data, permitted the immediate access to the test results and consequently allowed rapid patient treatment. Although, the POCT systems have gained the attraction of healthcare professionals, the excitement of this technology is often lost and the utilization of POCT systems in hospital-based clinics is limited. This is due to an assortment of obstacles (real and/or perceived) concerning the development and mainly the adoption of the POCT systems [66]. Initially, the technology that underpinned the POCT device utility was the major impending factor. However, the great progress of technological tools, allowing fabrication of MEMS, which integrate microchemical, micro-electronic and micro-fluidics structures, in one system have turned the focus to the clinical value of the data derived from POCT and how it is recorded and integrated within the care pathway [66]. According to Quinn et al. [66] and Wiencek et al. [67] the challenges - barriers related to the adoption of the POCT systems can be grouped to the following four categories:

(i) the device performance and data management issues. The inconsistencies in test results between POCT and central laboratory testing, the lack on interoperability between POCT devices and electronic medical record, as well as usability issues (i.e. interface, clarity of output, calibration and reference sources) of POCT devices impend their adoption.

(ii) the quality assurance and the regulatory issues related to POCT systems. The impediments to POCT implementation and adoption are the complex regulatory requirements related to accreditation and testing of POCT devices, the quality issues that appear due to misuse of POCT by users that are not trained or lack the appropriate competencies, the required frequency of quality control along with the necessary documentation, the cleaning and disinfection processes that should be performed, the documentation of the POCT results and the harmonization among central laboratory instruments and methods and POCT, as well as between different models of POCT devices.

(iii) staffing and operational issues. The barriers for the uptake of POCT devices belonging to this category are: (a) the inappropriate use of POCT, the reduced levels of staff satisfaction, leading, in some cases, to friction between clinical and laboratory staff groups, (b) the misuse of POCT reagents, (c) the reluctance of laboratory system to release the quality control and quality assurance responsibilities to a clinician, most probably, not formally trained, (d) the changes induced, by the utilization of POCT, in the clinical pathway and workflow, (e) the lack of the appropriate management structure for the accommodation of POCT systems and (f) the resistance of organization to change health service practice.

The inappropriate use of POCT, which might end to wrong results, is accompanied by medico-legal implications. The knowledge and understanding, by the POCT users, of the analytical principles, the quality assurance issues, the liability issues, the limitations of use, as well as of the interpretation of results are essential in order to achieve a reliable performance of the test. The support that is provided by the relevant laboratory department can contribute toward this direction [68]. Additionally, users of POCT should be aware of the legal responsibility they have in case they do not follow the instructions the manufacturer provides and/or they use instruments for purposes for which they are not intended.

This transfer of liability from the manufacturer to the user applies also to the users that use the POCT in their home for self-monitoring, an area of use of POCT devices that will become more common in the future. Such devices should be designed and manufactured taking into account the skills and the means available to users along with the influence resulting from variation that can be expected by the users' environment. Users of POCT devices, intended for self-monitoring, should ask for the confirmation of a medical professional for the interpretation of the results of the tests and the actions that should be followed [69].

(iv) economic issues. The obstacles for the integration of the POCT devices in clinical practice, related to economic issues, are the high cost of POCT in comparison to traditional central laboratory testing, the reimbursement policy that is followed, the inappropriate allocation of budgets for POCT, the high cost for initial implementation of a POCT system and the complexity-difficulty in estimating cost-effectiveness of a POCT system against traditional central laboratory testing methods.

In order to determine the impact of a new technology in healthcare, a factor that critically affects its adoption in clinical practice, three different aspects should be examined: i) the patient outcomes, ii) the process of care, and iii) the resource utilization. Despite the fact that POCT is generally perceived as more expensive (due to their faster turnaround time and the cost of the consumables) than a test that is performed in the central laboratory settings, the calculation of the actual cost cannot be directly estimated since the savings should not be limited in testing costs alone but other factors must also be considered (downstream savings). Unit cost of a test (POC or central laboratory test) should not drive the decision which one to be used. The decision should be taken based on a number of factors, many of which are unique to each hospital and/or care unit. Different types of cost analysis (cost minimization, cost effectiveness, cost consequences, cost utility and cost benefit 
analysis) should be performed towards this direction [32, 7072].

The lack of the clear view of the economic impact of POCT is attributed also to the reimbursement strategies employed in laboratory medicine. Reimbursement strategies usually take into account only the complexity of the test performance and its delivery as a cost per test service, while they ignore the resource utilization across the whole care pathway and the increase in the economic benefits that may be achieved for all the relevant stakeholders. The reason for the appearance of the reimbursement issues is the difficulties in the billing of POCT, in accurately capturing information, as well as in the lack of familiarity with regulatory guidelines. The problems in the billing of POCT are mainly caused by the multiple methodologies and Current Procedural Terminology (CPT) codes that are used for the same name. This mainly concerns the POCT devices that perform, at the same time, multiple results (multiple tests with one cartridge), where the one test is reimbursed while another may not be [32, 70-72].

Obstacles cannot be prioritized, either within or across the four categories, since the facts regarding the utilization of POCT systems change rapidly and various measures and solutions are followed in order to allay concerns and address the hurdles to hospital-based clinical adoption of POCT devices.

\section{CONCLUSIONS}

This manuscript gives an overview of POCT systems for HF. Both products available in the market and prototypes are introduced analyzing blood or saliva samples. Additionally, a summary of blood and saliva biomarkers that contribute to HF management (assessing risk for HF incidence, diagnosis of HF, risk stratification, screening of cardiac dysfunction, monitoring and guiding HF treatment) is presented. Finally, a taxonomy of POCT systems along with barriers and limitations in their adoption are briefly reported.

The potential of POCT systems to advance HF management and care across diverse clinical settings, as well as to enhance clinical research is widely accepted. Towards this direction contribute: (i) the technological advancement in the field of biosensors, microfluifics/paper based technology, biological MEMS, electric field-induced release and measurement and (ii) the close collaboration of representatives (i.e. health care providers, biomarker scientists, engineers, device manufacturers etc.) from different sectors leading to POCT systems meeting the ASSURED guidelines. Although the use of POCT has significantly increased, there are some challenges to be addressed in order to be fully adopted in different settings. Those challenges mainly concern the quality assurance and accreditation standards that the POCT devices should met. Following the five-step roadmap (Needs of identification, Biomarker selection and device design specification, Device development, Pilot testing, Prospective clinical testing) for the development of POCT systems for cardiovascular diseases that has been proposed by the National Heart, Lung, and Blood
Institute Working Group [20], can help creating clinically relevant POCT devices.

\section{ACKNOWLEDGMENT}

Research supported by the KardiaTool project that has received funding from the European Union's Horizon 2020 research and innovation program under the grant agreement No 768686 (http://www.kardiatool.eu/).

\section{REFERENCES}

[1] [1] World Health Organization - Cardiovascular diseases http://www.who.int/cardiovascular_diseases/en/.

[2] P. Ponikowski et al., ESC Scientific Document Group. 2016 ESC Guidelines for the diagnosis and treatment of acute and chronic heart failure: The Task Force for the diagnosis and treatment of acute and chronic heart failure of the European Society of Cardiology (ESC) Developed with the special contribution of the Heart Failure Association (HFA) of the ESC. Eur Heart J., 37(27):2129-2200, 2016.

[3] B. Ziaeian, G.C. Fonarow, Epidemiology and aetiology of heart failure, Nat. Rev. Cardiol., 13(6):368-78, 2016.

[4] J. Hu et al., Portable microfluidic and smartphone-based devices for monitoring of cardiovascular diseases at the point of care, Biotechnology Advances, 34:305-320, 2016.

[5] M. Shephard et al., A practical guide to global point-of-care testing. Shephard, Mark, editor.

[6] S.L. Chow et al., Role of Biomarkers for the Prevention, Assessment, and Management of Heart Failure: A Scientific Statement from the American Heart Association, Circulation, 135(22):e1054-e1091, 2017.

[7] W.H.W. Tang et al., National Academy of Clinical Biochemistry Laboratory Medicine practice guidelines: Clinical utilization of cardiac biomarker testing in heart failure, Circulation, 116(5):e99-109, 2007.

[8] Z. Huang et al., Diagnostic value of novel biomarkers for heart failure. A meta-analysis, Herz., 2018.

[9] R.S. Khan et al., Advancing Point-of-Care (PoC) Testing Using Human Saliva as Liquid Biopsy. Diagnostics, 7(3):E39, 2017.

[10] R.W. Hart et al., Point-of-care oral-based diagnostics, Oral Diseases, 17(8):745-752, 2011.

[11] S.A. Rehman et al., Role of Salivary Biomarkers in Detection of Cardiovascular Diseases (CVD), Proteoms, 5(21), 2017.

[12] K.E. Kaczor-Urbanowicz et al., Saliva diagnostics - Current views and directions, Exp. Biol. Med., 242: 459-472, 2017.

[13] Y. Ozbay et al., Obestatin is present in saliva: alterations in obestatin and ghrelin levels of saliva and serum in ischemic heart disease, BMB Rep, 41:55-61, 2008.

[14] R.T. Jr Chatterton et al., Salivary alpha-amylase as a measure of endogenous adrenergic activity, Clin. Physiol., 16:433-48, 1996.

[15] C.S. Miller et al., Utility of salivary biomarkers for demonstrating acute myocardial infarction, J. Dent. Res., 93:72S-9, 2014.

[16] Y.S. Shen et al., Diagnostic performance of initial salivary alphaamylase activity for acute myocardial infarction in patients with acute chest pain, J. Emerg. Med., 43:553-60, 2012.

[17] P.N. Floriano et al., Use of saliva-based nano-biochip tests for acute myocardial infarction at the point of care: a feasibility study, Clin. Chem., 55:1530-8, 2009.

[18] E.E. Tripoliti et al., A Computational Approach for the Estimation of Heart Failure Patients Status Using Saliva Biomarkers, Proceedings of the 39th Annual International Conference of the IEEE Engineering in Medicine and Biology Society, 2017, Korea.

[19] E.E. Tripoliti et al., Predicting Heart Failure patient events by exploiting saliva and breath biomarkers information, Proceedings of the 17th annual IEEE International Conference on BioInformatics and BioEngineering (BIBE2017), 2017, Washington, USA.

[20] K. King et al., Point-of-Care Technologies for Precision Cardiovascular Care and Clinical Research, JACC Basic. Transl. Sci., 1(1-2):73-86, 2016. 
[21] Wu et al., Low-cost tools for diagnosing and monitoring HIV infection in low-resource settings, Bulletin of the World Health Organization, 90:914-920, 2012.

[22] A. St John et al., Existing and emerging technologies for point-of-care testing. The Clinical Biochemist Reviews, 35:155-167, 2014.

[23] Y. Chen et al., Field-Effect Transistor Biosensor for Rapid Detection of Ebola Antigen, Sci Rep. 7: 10974, 2017.

[24] A. M. López-Marzoa, A. Merkoçi, Paper-based sensors and assays: a success of the engineering design and the convergence of knowledge areas, Lab Chip, 16: 3150-3176, 2016.

[25] T. Tian et al., Integrated paper-based microfluidic devices for point-ofcare testing, Anal. Methods, 10: 3567-3581, 2018.

[26] A.I. Barbosa, N.M. Reis, A critical insight into the development pipeline of microfluidic immunoassay devices for the sensitive quantitation of protein biomarkers at the point of care, Analyst, 142: 858-882, 2017.

[27] S.T. Sanjay et al., Biomarker detection for disease diagnosis using costeffective microfluidic platforms, Analyst, 140: 7062-7081, 2015.

[28] M.J. Jacinto et al., Enhancement of lateral flow assay performance by electromagnetic relocation of reporter particles, PLoS ONE, 13(1): e0186782, 2018.

[29] S.K. Vashist et al., Emerging Technologies for Next-Generation Pointof-Care Testing, Trends in Biotechnology, 33(11): 692-705, 2015.

[30] M. Mohammed, M.P.Y. Desmulliez, Lab-on-a-chip based immunosensor principles and technologies for the detection of cardiac biomarkers: a review, Lab Chip, 11:569-595, 2011.

[31] R.W. Hart et al., Point-of-care oral-based diagnostics, Oral Diseases, 17(8):745-752, 2011.

[32] K. Futrell, "Laboratory Point-of-Care Testing: A Future Outlook. POCT Progression \& the Importance of Connectivity", Orchard Software, 2015.

[33] M. Yang et al., Barcoded point-of-care bioassays, Chem. Soc. Rev., 2019, Advance.

[34] A.H.B. Wu, Recent advances in point-of-care diagnostics for cardiac markers, eJIFCC, 25(2):170-177, 2014.

[35] Muller et al., Cost-effectiveness of B-type natriuretic peptide testing in patients with acute dyspnea. Archives of Internal Medicine, 166(10):1081-1087, 2006.

[36] Alere Triage ${ }^{\circledR}$ - http://www.quidel.com/immunoassays/triage-testkits/triage-meterpro

[37] Roche Cobas h 232 - http://www.cobas.com/home/product/point-ofcare-testing/cobas-h-232.html

[38] ASPECT-PLUSTM ST2 - http://www.cruinnmedical.ie/cardiacbiomarkers/aspect-plus\%E2\%84\%A2-st2-.307.html

[39] i-STAT ${ }^{\circledR}$ - https://www.pointofcare.abbott/int/en/offerings/istat/istathandheld

[40] RapidPIA ${ }^{\circledR}$ - http://www.arkray.eu/english/news/2013/release33.html

[41] Meritas ${ }^{\circledR}$ - https://www.trinitybiotech.com/area/meritas-en/

[42] Pathfast ${ }^{\circledR}$ http://pathfast.com/docs/Polymedco\%20PATHFAST\%20Brochure.pdf

[43] RAMP® - http://responsebio.com/products/ramp-reader

[44] Samsung LABGEO ${ }^{\circledR}$

http://www.samsungmedicalsolution.com/en/common/productDetail/view?pro ductId=175\&productTabId=benefit\&depth_gb=ivd

[45] SHIONOSPOT ${ }^{\circledR}$ http://www.saito.tv/e/lsp/LSP_GuideList/English/Shionogi.htm

[46] Stratus ${ }^{\circledR} \quad$ CS $\quad$ Analyzer https://www.healthcare.siemens.com/cardiac/cardiac-systems/stratuscs-acute-care

[47] J. Ishida et al., Comparison of analytical performance of two single-step measurement devices of B-type natriuretic Peptide, Int Heart J., 53(5):320-3, 2012.

[48] C.M. Bonebreak et al., The potential of salivary point of care diagnostics, J. Appl. Oral Sci., 19(4), 2011.

[49] Z. Khurshid, Salivary point-of-care technology, Eur. J. Dent., 12(1):1-2, 2018.

[50] K.E. Kaczor-Urbanowicz et al., Saliva diagnostics - Current views and directions, Exp. Biol. Med., 242:459-472, 2017.

[51] N. Rathnayake et al., Salivary Biomarkers for Detection of Systemic Diseases, PLoS ONE., 8:e61356, 2013.
[52] C.S. Miller et al., Utility of Salivary Biomarkers for Demonstrating Acute Myocardial Infarction, J. Dent. Res., 93:72S-79S, 2014.

[53] J.Y.Y. Foo et al., NT-ProBNP Levels in Saliva and Its Clinical Relevance to Heart Failure, PLoS ONE., 7:e48452, 2012.

[54] C. Labat et al., Inflammatory mediators in saliva associated with arterial stiffness and subclinical atherosclerosis, J. Hypertens., 31:2251-2258, 2013.

[55] J.D. Foley et al., Oral fluids that detect cardiovascular disease biomarkers, Oral Surg. Oral Med. Oral Pathol. Oral Radiol., 114:207214, 2012.

[56] J.D. Foley et al., Salivary biomarkers associated with myocardial necrosis: Results from an alcohol septal ablation model, Oral Surg. Oral Med. Oral Pathol. Oral Radiol., 114:616-623, 2012.

[57] I. Mirzaii-Dizgah et al., Salivary troponin I as an indicator of myocardial infarction, Indian J. Med. Res., 138:861-865, 2013.

[58] N. Christodoulides et al., Application of microchip assay system for the measurement of C-reactive protein in human saliva, Lab Chip., 5(3):2619, 2005.

[59] N. Christodoulides et al., Programmable bio-nanochip technology for the diagnosis of cardiovascular disease at the point-of-care, Methodist DeBakey Cardiovasc. J., 8:6-12, 2012.

[60] G. Karanasiou et al., HEARTEN: An integrated mHealth platform for holistic HF management, Proceedings of the IEEE Conference on Biomedical and Health Informatics (BHI2018), 4-7 March 2108, Las Vegas, Nevada, USA.

[61] R. Pruna et al., A low-cost and miniaturized potentiostat for sensing of biomolecular species such as TNF- $\alpha$ by electrochemical impedance spectroscopy, Biosensors and Bioelectronics, 100:533-540, 2018.

[62] L. Barhoumi et al., A novel chronoamperometric immunosensor for rapid detection of TNF- $\alpha$ in human saliva, Sensors and Actuators B: Chemical, 266: 477-484, 2018.

[63] F.G. Bellagambi et al., Electrochemical biosensor platform for TNF- $\alpha$ cytokines detection in both artificial and human saliva: Heart failure, Sensors and Actuators B: Chemical, 251:1026-1033, 2018.

[64] A. Baraket et al., A fully integrated electrochemical biosensor platform fabrication process for 58 detection, Biosensors and Bioelectronics, 93:170-175, 2017.

[65] A. Baraket et al., A flexible electrochemical micro lab-on-chip: application to the detection of interleukin-10, Microchimica Acta, 183:2155-2162, 2016.

[66] A.D. Quinn et al., Barriers to hospital-based clinical adoption of pointof-care testing (POCT): A systematic narrative review, Crit Rev Clin Lab Sci., 53(1):1-12, 2016.

[67] J. Wiencek et al., Issues in the practical implementation of POCT: overcoming challenges, Expert Rev Mol Diagn., 16(4):415-22, 2016.

[68] I. Farrance, Policies, Procedures and Guidelines for Point-Of-Care Testing, Prepared on behalf of the RCPA Quality Assurance Programs Pty Ltd, 2014.

[69] A. John et al., The Evidence to Support Point-of-Care Testing, Clin. Biochem. Rev., 31:111-119, 2010

[70] A. John et al., Economic Evidence and Point-of-Care Testing, Clin. Biochem. Rev., 34:61-74, 2013.

[71] E. Lee-Lewandrowski et al., Perspectives on Cost and Outcomes for Point-of-Care Testing, Clin. Lab. Med., 29:479-489, 2009.

[72] B. MacMillan, Reimbursement for Point-of-Care Testing, Point of Care, 1(4):253-258, 2002.

[73] R.S. Velagaleti et al., Multimarker approach for the prediction of heart failure incidence in the community. Circulation, 122:1700-1706, 2010.

[74] F.P. Brouwers et al., Clinical risk stratification optimizes value of biomarkers to predict new-onset heart failure in a communitybased cohort, Circ Heart Fail., 7:723-731, 2014.

[75] T.J. Wang et al., Prognostic utility of novel biomarkers of cardiovascular stress: the Framingham Heart Study, Circulation, 126:1596-1604, 2012.

[76] C.R. deFilippi et al., Association of serial measures of cardiac troponin $\mathrm{T}$ using a sensitive assay with incident heart failure and cardiovascular mortality in older adults, JAMA, 304:2494-2502, 2010.

[77] T.J. Wang et al., Plasma natriuretic peptide levels and the risk of cardiovascular events and death, N Engl J Med., 350:655-663, 2004. 
[78] J.A. de Lemos et al., Association of troponin T detected with a highly sensitive assay and cardiac structure and mortality risk in the general population, JAMA, 304:2503-2512, 2010.

[79] S.L. Seliger et al., Older adults, "malignant" left ventricular hypertrophy, and associated cardiac-specific biomarker phenotypes to identify the differential risk of new-onset reduced versus preserved ejection fraction heart failure: CHS (Cardiovascular Health Study), JACC Heart Fail., 3:445-455, 2015.

[80] T.J. Wang et al., Multiple biomarkers for the prediction of first major cardiovascular events and death, N Engl J Med., 355:2631-2639, 2006.

[81] C.W. Yancy et al., 2013 ACCF/AHA guideline for the management of heart failure: a report of the American College of Cardiology Foundation/American Heart Association Task Force on Practice Guidelines, Circulation, 128:e240-327, 2013.

[82] J.J. McMurray et al., ESC guidelines for the diagnosis and treatment of acute and chronic heart failure 2012: the Task Force for the Diagnosis and Treatment of Acute and Chronic Heart Failure 2012 of the European Society of Cardiology, Eur Heart J., 33:1787-1847, 2012.

[83] B. Steinhart et al., Improving the diagnosis of acute heart failure using a validated prediction model, J Am Coll Cardiol., 54:1515-1521, 2009.

[84] Y. Iwanaga et al., B-type natriuretic peptide strongly reflects diastolic wall stress in patients with chronic heart failure: comparison between systolic and diastolic heart failure, J Am Coll Cardiol., 47:742-748, 2006.

[85] P.U. Gandhi et al., Prognostic usefulness of insulin-like growth factorbinding protein 7 in heart failure with reduced ejection fraction: a novel biomarker of myocardial diastolic function?, Am J Cardiol., 114:15431549, 2014.

[86] P.U. Gandhi et al., Insulin-like growth factor-binding protein-7 as a biomarker of diastolic dysfunction and functional capacity in heart failure with preserved ejection fraction: results from the RELAX trial, JACC Heart Fail., 4:860-869, 2016.

[87] M.R. Zile et al., Plasma biomarkers that reflect determinants of matrix composition identify the presence of left ventricular hypertrophy and diastolic heart failure, Circ Heart Fail., 4:246-256, 2011.

[88] R.S. McKelvie et al., Baseline plasma NT-proBNP and clinical characteristics: results from the irbesartan in heart failure with preserved ejection fraction trial, J Card Fail., 16:128-134, 2010.

[89] P.S. Jhund et al., Changes in N-terminal pro-B-type natriuretic peptide levels and outcomes in heart failure with preserved ejection fraction: an analysis of the I-Preserve study, Eur J Heart Fail., 17:809-817, 2015.

[90] A. Maisel et al., Primary results of the HABIT Trial (Heart Failure Assessment With BNP in the Home), J Am Coll Cardiol., 61:1726-1735, 2013.

[91] J. Bartunek et al., Nonmyocardial production of ST2 protein in human hypertrophy and failure is related to diastolic load, J Am Coll Cardiol., 52:2166-2174, 2008.

[92] Y.C. Wang et al., Soluble ST2 as a biomarker for detecting stable heart failure with a normal ejection fraction in hypertensive patients, J Card Fail., 19:163-168, 2013.

[93] S. Manzano-Fernández et al., Usefulness of soluble concentrations of interleukin family member ST2 as predictor of mortality in patients with acutely decompensated heart failure relative to left ventricular ejection fraction, Am J Cardiol., 107:259-267, 2011.

[94] S.U. Rehman et al., Characteristics of the novel interleukin family biomarker ST2 in patients with acute heart failure, J Am Coll Cardiol., 52:1458-1465, 2008.

[95] D.M. Gopal et al., Relationship of plasma galectin-3 to renal function in patients with heart failure: effects of clinical status, pathophysiology of heart failure, and presence or absence of heart failure, J Am Heart Assoc., 1:e000760, 2012.

[96] C.R. deFilippi et al., Galectin-3 in heart failure: linking fibrosis, remodeling and progression, Eur Cardiol., 6:33-36, 2010.

[97] R.A. de Boer et al., Predictive value of plasma galectin-3 levels in heart failure with reduced and preserved ejection fraction, Ann Med., 43:6068, 2011.

[98] R.V. Shah et al., Galectin-3, cardiac structure and function, and long term mortality in patients with acutely decompensated heart failure, Eur J Heart Fail., 12:826-832, 2010.
[99] R.R. van Kimmenade et al., Utility of amino-terminal pro-brain natriuretic peptide, galectin-3, and apelin for the evaluation of patients with acute heart failure, J Am Coll Cardiol., 48:1217-1224, 2006.

[100] F.J. Carrasco-Sánchez et al., Predictive value of serum galectin-3 levels in patients with acute heart failure with preserved ejection fraction, Int $\mathrm{J}$ Cardiol., 169:177-182, 2013.

[101] R. Martos et al., Diastolic heart failure: evidence of increased myocardial collagen turnover linked to diastolic dysfunction, Circulation, 115:888$895,2007$.

[102] A. González et al., Filling pressures and collagen metabolism in hypertensive patients with heart failure and normal ejection fraction, Hypertension, 55:1418-1424, 2010.

[103] R. Martos et al., Diagnosis of heart failure with preserved ejection fraction: improved accuracy with the use of markers of collagen turnover, Eur J Heart Fail., 11:191-197, 2009.

[104] E. Barasch et al., Association between elevated fibrosis markers and heart failure in the elderly: the Cardiovascular Health Study, Circ Heart Fail., 2:303-310, 2009.

[105] H. Krum et al., Relation of peripheral collagen markers to death and hospitalization in patients with heart failure and preserved ejection fraction: results of the I-PRESERVE collagen substudy, Circ Heart Fail., 4:561-568, 2011.

[106] T. Kitahara et al., Serum carboxy-terminal telopeptide of type I collagen (ICTP) predicts cardiac events in chronic heart failure patients with preserved left ventricular systolic function, Circ J., 71:929-935, 2007.

[107] S.H. Ahmed et al., Matrix metalloproteinases/tissue inhibitors of metalloproteinases: relationship between changes in proteolytic determinants of matrix composition and structural, functional, and clinical manifestations of hypertensive heart disease, Circulation, 113:2089-2096, 2006.

[108] L.L. Ng et al., Myeloperoxidase and C-reactive protein augment the specificity of B-type natriuretic peptide in community screening for systolic heart failure, Am Heart J., 152:94-101, 2006.

[109] S. Jeyaseelan et al., A critical re-appraisal of different ways of selecting ambulatory patients with suspected heart failure for echocardiography, Eur J Heart Fail., 9:55-61, 2007.

[110] W.H. Tang et al., Risk stratification for patients undergoing nonurgent percutaneous coronary intervention using N-terminal pro-B-type natriuretic peptide: a Clopidogrel for the Reduction of Events During Observation (CREDO) sub-study, Am Heart J., 153:36-41, 2007.

[111] A.H. Wu, Serial testing of B-type natriuretic peptide and NTproBNP for monitoring therapy of heart failure: the role of biologic variation in the interpretation of results, Am Heart J., 152:828-34, 2006.

[112] P. Jourdain et al., Plasma Brain Natriuretic Peptide-Guided Therapy to Improve Outcome in Heart Failure: The STARS-BNP Multicenter Study, J Am Coll Cardiol., 49:1733-1739, 2007.

[113] L. Beck-da-Silva et al., BNP-guided therapy not better than expert's clinical assessment for beta-blocker titration in patients with heart failure, Congest Heart Fail., 11:248-53, 2005.

[114] J.G. Lainchbury et al., NTproBNP-guided drug treatment for chronic heart failure: design and methods in the "BATTLESCARRED" trial, Eur J Heart Fail., 8:532-8, 2006.

[115] H.P. Brunner-La Rocca et al., Management of elderly patients with congestive heart failure - design of the Trial of Intensified versus standard Medical therapy in Elderly patients with Congestive Heart Failure (TIME-CHF), Am Heart J., 151:949-55, 2006.

[116] P. Jourdain, G. Jondeau, F. Funck et al., Plasma brain natriuretic peptideguided therapy to improve outcome in heart failure. The STARS-BNP Multicenter Study, Journal of the American College of Cardiology, 49(16): 1733-1739, 2007.

[117] L. Leto, M. Testa, M. Feola, Correlation between B-Type Natriuretic Peptide and Functional/Cognitive Parameters in Discharged Congestive Heart Failure Patients, International Journal of Endocrinology, volume 2015, Article ID 239136, 7 pages, 2015. 
Table I: Blood biomarkers related to HF.

\begin{tabular}{|c|c|}
\hline Task & Assessing risk for incidence of $\mathrm{HF}$ \\
\hline Biomarker(s) & BNP, NT-proBNP, cTn-I, cTn-T, sST2, GAL-3, GDF-15, CRP, cystatin-C \\
\hline Suggestion(s) & $\begin{array}{l}\text { AHA [6]: } \\
\text { 1. "In community based populations, measurement of BNP or NT-proBNP or markers for myocardial injury (cTn- } \\
\text { I, cTn-T) alone adds prognostic information to standard risk factors for prediction new-onset of HF" } \\
\text { 2. "Measurement of several new biomarkers including } S S T 2, G A L-3, G D F-15 \text {, and markers of renal function, alone } \\
\text { or in a mutli-marker strategy, may be useful for providing additional risk stratification" }\end{array}$ \\
\hline Related literature & {$[73-80]$} \\
\hline Task & Diagnosis of $\mathrm{HF}$ \\
\hline Biomarker(s) & $\begin{array}{l}\text { BNP, NT-proBNP, IGF-7, sST2, GAL-3, PINP, PIIINP, PICP, CITP, MMP-1, MMP-2, MMP-8, MMP-9, TIMP- } \\
\text { 1, TIMP-4 }\end{array}$ \\
\hline Suggestion(s) & $\begin{array}{l}\text { AHA [6]: } \\
\text { 1. "Measurement of BNP and NT-proBNP is useful to support clinical judgement for the diagnosis of ambulatory } \\
\text { and acute decompensated patients, especially in the setting of clinical uncertainty" } \\
\text { NACBL [7]: } \\
\text { 1. "BNP or NT-proBNP testing can be used in the acute setting to rule out or to confirm the diagnosis of heart } \\
\text { failure among patients presenting with ambiguous signs and symptoms. (Class I, Level of Evidence: A)" } \\
\text { 2. "BNP and NT-proBNP testing can be helpful to exclude the diagnosis of heart failure among patients with } \\
\text { signs and symptoms suspicious of heart failure in the non-acute setting. (Class IIa, Level of Evidence: C)" } \\
\text { 3. "In diagnosing patients with heart failure, routine blood BNP or NT-proBNP testing for patients with an } \\
\text { obvious clinical diagnosis of heart failure is not recommended. (Class III, Level of Evidence: C)" } \\
\text { 4. "In diagnosing patients with heart failure, blood BNP or NT-proBNP testing should not be used to replace } \\
\text { conventional clinical evaluation or assessment of the degree of left ventricular structural or functional } \\
\text { abnormalities (e.g., echocardiography, invasive hemodynamic assessment). (Class III, Level of Evidence: C)" }\end{array}$ \\
\hline Related literature & {$[81-83]$} \\
\hline Task & Prognosis of $\mathrm{HF}$ - Risk stratification \\
\hline \multirow{3}{*}{ Biomarker(s) } & Chronic HF: BNP, NT-proBNP, cTn-T, cTn-I, sST2, GAL-3, mid-regional pro-adrenomedullin \\
\hline & Acute HF: BNP, NT-proBNP, cTn-T, cTn-I, sST2, GAL-3, mid-regional pro-adrenomedullin, CRP, copeptin \\
\hline & $\begin{array}{l}\text { HF with preserved ejection fraction: BNP, NT-proBNP, cTn-T, cTn-I, sST2, GAL-3, IGF-7, PINP, PIIINP, PICP, } \\
\text { CITP }\end{array}$ \\
\hline Suggestion(s) & $\begin{array}{l}\text { AHA [6]: } \\
\text { 1. "Measurement of BNP or NT-proBNP and cTn at the time of presentation is useful for establishing prognosis } \\
\text { or disease severity in patients with acutely decompensated HF" } \\
\text { 2. "Measurement of other clinically available tests such as biomarkers of myocardial injury or fibrosis is } \\
\text { reasonable for additive risk stratification in patients with acutely decompensated HF" } \\
\text { 3. "Measurement of pre-discharge BNP or NT-proBNP during an HF hospitalization can be useful for } \\
\text { establishing post-discharge prognosis" } \\
\text { NACBL [7]: } \\
\text { 1. "Blood BNP or NT-proBNP testing can provide a useful addition to clinical assessment in selected situations } \\
\text { when additional risk stratification is required. (Class IIa, Level of Evidence: A)" } \\
\text { 2. "Serial blood BNP or NT-proBNP concentrations may be used to track changes in risk profiles and clinical } \\
\text { status among patients with heart failure in selected situations where additional risk stratification is required. } \\
\text { (Class IIa, Level of Evidence: B)" } \\
\text { 3. Cardiac troponin testing can identify patients with heart failure at increased risk beyond the setting of acute } \\
\text { coronary syndromes. (Class IIb, Level of Evidence: B) } \\
\text { 4. Routine blood biomarker testing for the sole purpose of risk stratification in patients with heart failure is not } \\
\text { warranted. (Class III, Level of Evidence: B) }\end{array}$ \\
\hline Related literature & {$[75,81,82,84-107]$} \\
\hline Task & Screening of cardiac dysfunction \\
\hline Biomarker(s) & BNP, NT-proBNP \\
\hline Suggestion(s) & $\begin{array}{l}\text { NACBL [7]: } \\
\text { 1. "Blood BNP or NT-proBNP testing can be helpful to identify selected patients with left ventricular systolic } \\
\text { dysfunction in the post-infarction setting or to identify patients at high risk of developing heart failure (e.g., } \\
\text { history of myocardial infarction, diabetes mellitus). However, the diagnostic ranges and cost-effectiveness in } \\
\text { different populations remain controversial. (Class IIb, Level of Evidence: B)" } \\
\text { "Routine blood natriuretic peptide (BNP or NTproBNP) testing is not recommended for screening large } \\
\text { asymptomatic patient populations for left ventricular dysfunction. (Class III, Level of Evidence: B)" }\end{array}$ \\
\hline Related literature & {$[107-110]$} \\
\hline
\end{tabular}




\begin{tabular}{|c|c|}
\hline Task & Monitoring - Guiding HF therapy \\
\hline Biomarker(s) & BNP, NT-proBNP \\
\hline Suggestion(s) & $\begin{array}{l}\text { AHA [6]: } \\
\text { 1. "BNP-or NT-proBNP-guided HF therapy is of uncertain benefit in clinical practice and cannot be universally } \\
\text { advised. There are some data to support the use of serial measurement of biomarkers as a means to achieve } \\
\text { ideal doses of guideline determined medical therapy, but the influence of this approach outside specialized } \\
\text { HF centers with highly structured HF disease management programs is unknown" } \\
\text { 2. "The usefulness of serial measurement of BNP or NT-proBNP to reduce hospitalization or mortality in patients } \\
\text { with HF is not well established" } \\
\text { "The response of NT-proBNP to neprilysin inhibition with concomitant renin-angiotensin-aldosterone system } \\
\text { inhibition is associated with positive clinical outcomes but should not be used as a surrogate to guide treatment } \\
\text { with an angiotensin-receptor/neprilysin inhibitor compound until prospectively acquired randomized data are } \\
\text { available" } \\
\text { "The usefulness of BNP- or NT-proBNP-guided therapy for acutely decompensated HF is not well } \\
\text { established" } \\
\text { "BNP or NT-proBNP concentrations collected after treatment may be useful for prognosis in hospitalized } \\
\text { patients with acutely decompensated HF" } \\
\text { NACBL [7]: } \\
\text { 1. "Routine blood BNP or NT-proBNP testing is not warranted for making specific therapeutic decisions for } \\
\text { patients with acute or chronic heart failure because of the still emerging but incomplete data as well as intra- } \\
\text { and inter-individual variations. (Class III, Level of Evidence: B)" }\end{array}$ \\
\hline Related literature & {$[81,111-118]$} \\
\hline
\end{tabular}


Table II: Commercially available POCT devices providing quantitative measurements of cardiovascular biomarker(s) by analyzing blood samples - PART A

\begin{tabular}{|c|c|c|c|c|c|c|c|}
\hline Brand name & Biomarker & Response time & Sample & Containers & Data input & User interface & Connectivity/Communication \\
\hline \multirow[t]{2}{*}{ Alere Triage ${ }^{\circledR}[36]$} & $\begin{array}{l}\text { BNP, } \\
\text { NT-proBNP }\end{array}$ & $\sim 15-20$ minutes & blood, plasma or urine & Paper based & $\begin{array}{l}\text { Barcode reader for } \\
\text { patient and operator ID } \\
\text { with alphanumeric } \\
\text { capability }\end{array}$ & $\begin{array}{l}\text { Screen and } \\
\text { buttons }\end{array}$ & $\begin{array}{l}\text { LIS compatibility, RS-232 computer } \\
\text { interface port }\end{array}$ \\
\hline & \multicolumn{7}{|c|}{ Other features: ID and QC lockouts including unauthorized users, Multiple comprehensive connectivity options, Low total operating costs, Integrated printer. } \\
\hline \multirow[t]{2}{*}{$\begin{array}{l}\text { Roche Cobas h } 232 \\
\text { [37] }\end{array}$} & $\begin{array}{l}\text { Troponin T, } \\
\text { NT-proBNP } \\
\text { D-dimer, } \\
\text { Myoglobin, } \\
\text { CK-MB }\end{array}$ & $\sim 8-12$ minutes & $\begin{array}{l}150 \mu \mathrm{L} \text { heparinized } \\
\text { whole blood }\end{array}$ & Strip & Barcode scanner & $\begin{array}{l}\text { Color touch } \\
\text { screen }\end{array}$ & $\begin{array}{l}\text { QR code WiFi USB (handheld base } \\
\text { unit and computer are required) }\end{array}$ \\
\hline & \multicolumn{7}{|c|}{ Other features: Supported communication interfaces: IR-printers, POCT1-A communication via docking station, POCT1-A communication via WiFi, QR code } \\
\hline \multirow[t]{2}{*}{$\begin{array}{l}\text { ASPECT-PLUS } \\
\text { ST2 [38] }\end{array}$} & $* \quad$ ST2 & $\sim 20$ minutes & $35 \mu \mathrm{L}$ EDTA plasma & $\begin{array}{c}\text { A disposable, } \\
\text { single use } \\
\text { cassette }\end{array}$ & $\begin{array}{l}\text { Internal reader check on } \\
\text { every initialization }\end{array}$ & $\begin{array}{l}\text { Screen and } \\
\text { buttons }\end{array}$ & $\begin{array}{l}\text { LIS connectivity } \\
\text { RFID for automatic upload of lot } \\
\text { specific information }\end{array}$ \\
\hline & \multicolumn{7}{|c|}{ Other features: Factory calibrated, QC lockout, Built-in printer } \\
\hline \multirow[t]{2}{*}{ i-STAT $®[39]$} & $\begin{array}{l}\text { CTnI, } \\
\text { CK-MB } \\
\text { BNP }\end{array}$ & $\sim 2$ minutes & $\begin{array}{c}2-3 \text { drops of blood (65-95 } \\
\mu \mathrm{l})\end{array}$ & Cartridge & Barcode scanner & $\begin{array}{l}\text { Screen and } \\
\text { buttons }\end{array}$ & $\begin{array}{l}\text { Downloader/Recharger available for } \\
\text { use with ethernet cabling (network } \\
\text { format) and direct wiring (serial } \\
\text { format), network downloader converts } \\
\text { serial data via IR to TCP/IP, AME, } \\
\text { ASTM, HL7, also wireless transfer to } \\
\text { POC Data Manager which is } \\
\text { connected to the LIS/KIS }\end{array}$ \\
\hline & \multicolumn{7}{|c|}{ Other features: Lab-quality results fast, Simple to use, Broad test menu, Comprehensive support } \\
\hline \multirow[t]{2}{*}{ RapidPIA® $[40]$} & $*$ BNP & $\sim 15$ minutes & blood & - & Barcode scanner & $\begin{array}{l}\text { LCD Screen } 8 \\
\text { lines and } \\
\text { buttons }\end{array}$ & Interface: USB, RS-232C \\
\hline & \multicolumn{7}{|c|}{ Other features: thermal printer } \\
\hline \multirow[t]{2}{*}{$\operatorname{Meritas} ®[41]$} & $\begin{array}{l}* \text { Troponin I } \\
* \text { BNP }\end{array}$ & $\sim 15$ minutes & $\begin{array}{l}200 \mu \mathrm{l} \text { Whole blood, } \\
\text { lithium heparin and } \\
\text { EDTA plasma }\end{array}$ & $\begin{array}{l}\text { Single use } \\
\text { disposable test } \\
\text { cartridges }\end{array}$ & Barcode scanner & $\begin{array}{l}\text { Screen and } \\
\text { buttons }\end{array}$ & Connectivity to LIS/HIS \\
\hline & \multicolumn{7}{|l|}{ Other features: - } \\
\hline \multirow[t]{2}{*}{ Pathfast ${ }^{\circledR}[42]$} & $\begin{array}{l}\text { Troponin I, } \\
\text { NTproBNP, } \\
\text { CK-MB, } \\
\text { D-Dimer, } \\
\text { High sensitive C- } \\
\text { reactive Protein } \\
\text { (hsCRP), } \\
\text { Myoglobin } \\
\text { simultaneously }\end{array}$ & $\sim 17$ minutes & $\begin{array}{l}100 \mu 1 \text { whole blood, } \\
\text { serum or plasma }\end{array}$ & Reagent cartridge & Barcode scanner & $\begin{array}{l}\text { LCD touch } \\
\text { screen }\end{array}$ & $\begin{array}{c}\text { Data transfer: ASTM standard } \\
\text { PC Integrated Interface: RS-232C and } \\
\text { Ethernet Port }\end{array}$ \\
\hline & \multicolumn{7}{|c|}{ Other features: Integrated printer } \\
\hline $\mathbf{R A M P}{ }^{8}[43]$ & $\begin{array}{l}\text { NT-proBNP, } \\
\text { Troponin I, } \\
\text { D-Dimer, } \\
\text { CK-MB, } \\
\text { Myoglobin } \\
\end{array}$ & $\sim 15$ minutes & blood & $\begin{array}{l}\text { Single use } \\
\text { disposable test } \\
\text { cartridges }\end{array}$ & Barcode scanner & $\begin{array}{l}\text { Screen and } \\
\text { buttons }\end{array}$ & $\begin{array}{l}\text { LIS compatibility, RS-232 serial } \\
\text { communication; mini DIN for barcode } \\
\text { wand }\end{array}$ \\
\hline
\end{tabular}




\begin{tabular}{|c|c|c|c|c|c|c|c|}
\hline Brand name & Biomarker & Response time & Sample & Containers & Data input & User interface & Connectivity/Communication \\
\hline \multirow[t]{2}{*}{$\begin{array}{l}\text { Samsung LABGEO }{ }^{\circledR} \\
{[44]}\end{array}$} & 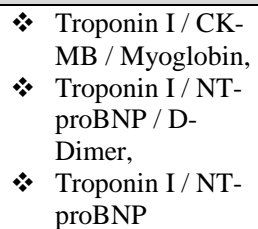 & $\sim 20$ minutes & $\begin{array}{l}500 \mu 1 \text { Whole Blood or } \\
\text { Plasma }\end{array}$ & Lab on a disc & Barcode scanner & $\begin{array}{l}\text { Touch screen } \\
\text { display }\end{array}$ & $\begin{array}{l}\text { USB, Ethernet 10/100 Base-T, W- } \\
\text { LAN, HIS-Standard-Protocols (HL7, } \\
\text { ASTM, POCT1-A) }\end{array}$ \\
\hline & $\begin{array}{l}\text { Other features: Supp } \\
\text { Information Systems ( }\end{array}$ & $\begin{array}{l}\text { LAN connectivi } \\
\text { ), PCs and mobile }\end{array}$ & $\begin{array}{l}\text { use of multiple exter } \\
\text { nes or other mobile devi }\end{array}$ & $\begin{array}{l}\text { evices, includin } \\
\text { r efficient datab }\end{array}$ & $\begin{array}{l}\text { Memory, Wi-Fi U } \\
\text { lagement, transfer }\end{array}$ & $\begin{array}{l}\text { ngle and barcode } \\
\text { lts for reference, }\end{array}$ & $\begin{array}{l}\text { anner devices, connection to Hospital } \\
\text { ification and database building. }\end{array}$ \\
\hline \multirow{2}{*}{ SHIONOSPOT ${ }^{\circledR}$ [45] } & $*$ BNP & $\sim 15$ minutes & Whole blood & - & - & - & - \\
\hline & Other features: Meas & nent range: $6-200$ & ml, Number of tests: 25 & kit, Storage tem & , Validity: $2-8^{\circ} \mathrm{C}$, & & \\
\hline \multirow[t]{2}{*}{$\begin{array}{l}\text { Stratus }{ }^{\circledR} \text { CS Analyzer } \\
{[46]}\end{array}$} & $\begin{array}{l}\text { Troponin I, } \\
\text { D-Dimer, } \\
\text { NT-proBNP, } \\
\text { Cardiophase } \\
\text { hsCRP, } \\
\text { CK-MB, } \\
\text {. Myoglobin }\end{array}$ & $\begin{array}{c}\sim 14 \text { minutes to } \\
\text { first result, and } \\
\sim 4 \text { minutes for } \\
\text { each subsequent } \\
\text { result }\end{array}$ & blood & Cartridge & Barcode scanner & $\begin{array}{l}\text { Touch screen } \\
\text { display }\end{array}$ & $\begin{array}{l}\text { Bidirectional connectivity through } \\
\text { network connection, unidirectional }\end{array}$ \\
\hline & $\begin{array}{l}\text { Other features: Ele } \\
\text { expiration notificatic }\end{array}$ & $\begin{array}{l}\mathrm{QC} \text { with progr } \\
\text { ord protection }\end{array}$ & $\begin{array}{l}\text { le time lockout, Patier } \\
\text { inced setup functions }\end{array}$ & nd/or sample & sample collectio & try, Unauthoriz & operator lockout capability TestPak lot \\
\hline
\end{tabular}


Table III: Commercially available POCT devices providing quantitative measurements of cardiovascular biomarker(s) by analyzing blood samples - PART B.

\begin{tabular}{|c|c|c|c|c|}
\hline Brand name & Detection method & $\begin{array}{c}\text { Operating environment } \\
\text { (hospital, doctor's office, at } \\
\text { home) }\end{array}$ & Dimensions (mass, volume) & LOC description \\
\hline Alere Triage ${ }^{\circledR}[36]$ & Immunofluorescence & Hospitals, doctor's offices & $\begin{array}{c}7 \mathrm{~cm}(\mathrm{H}) \times 19 \mathrm{~cm}(\mathrm{~W}) \times 22,5 \mathrm{~cm}(\mathrm{D}), \\
0,7 \mathrm{~kg}\end{array}$ & $\begin{array}{l}\text { Drops of an anticoagulated whole blood or plasma specimen are } \\
\text { added to the sample port. The whole blood cells are separated from } \\
\text { the plasma using a filter. The specimen reacts with fluorescent } \\
\text { antibody conjugates. A capillary action allows the flow to be } \\
\text { performed. Complexes of each fluorescent antibody conjugate are } \\
\text { captured on discrete zones specific to the analyte. The Alere Triage } \\
\text { BNP Test contains all reagents necessary for the quantification of } \\
\text { BNP in EDTA anticoagulated whole blood or plasma specimens. }\end{array}$ \\
\hline Roche Cobas h 232 [37] & - & Hospitals, doctor's office & $244 \times 105 \times 51 \mathrm{~mm}$ & $\begin{array}{l}\text { Troponin T, } \\
\text { Measuring range: } 50-2,000 \mathrm{ng} / \mathrm{L}(50-100 \mathrm{ng} / \mathrm{L} \text { is quantitative } \\
\text { range indicating result is between } 50-100 \mathrm{ng} / \mathrm{L}) \\
\text { Cut-off values: } \\
<50 \mathrm{ng} / \mathrm{L}=\mathrm{Low} \text { risk, } \\
50-100 \mathrm{ng} / \mathrm{L}=\text { Medium risk, } \\
>100=\text { High risk } \\
\quad \text { NT-proBNP } \\
\text { Measuring range: } 60-9,000 \mathrm{pg} / \mathrm{mL} \\
\text { Cut-off values: } \\
<125 \mathrm{pg} / \mathrm{mL}=\text { Exclusion of Non-acute heart failure, } \\
<300 \text { pg/mL }=\text { Exclusion of acute heart failure } \\
\text { Consideration of age-stratified cut-points for diagnosis of (=CHF } \\
\text { likely considering confounding factors): } \\
<50 \text { years }<450 \mathrm{pg} / \mathrm{mL} \text {, } \\
50-75 \text { years }>900 \mathrm{pg} / \mathrm{mL}, \\
>75 \text { years }>1,800 \mathrm{pg} / \mathrm{mL} \\
\quad \text { D-dimer, } \\
\text { Measuring range: } 0.1-4.0 \mu \mathrm{g} / \mathrm{mL} \\
\text { Cut-off values: } 0.5 \mu \mathrm{g} / \mathrm{mL} \\
\quad \text { Myoglobin, } \\
\text { Measuring range: } 30-700 \mathrm{ng} / \mathrm{mL} \\
\text { Cut-off values: Female: } 7-64 \mathrm{ng} / \mathrm{mL}, \mathrm{Male:} 16-76 \mathrm{ng} / \mathrm{mL} \\
\quad \text { CK-MB } \\
\text { Measuring range: } 1.0-40.0 \mathrm{ng} / \mathrm{mL} \\
\text { Cut-off values: Female: } 4 \mathrm{ng} / \mathrm{mL}, \mathrm{Male:} 7 \mathrm{ng} / \mathrm{mL}\end{array}$ \\
\hline $\begin{array}{l}\text { ASPECT-PLUS }{ }^{\text {TM }} \text { ST2 } \\
{[38]}\end{array}$ & $\begin{array}{c}\text { Quantitative fluorescent } \\
\text { lateral flow } \\
\text { immunoassay format }\end{array}$ & Hospitals & - & $\begin{array}{l}\text { The ASPECT-PLUS ST2 Test is a quantitative sandwich } \\
\text { monoclonal lateral flow immunoassay. Serum, venous EDTA, or } \\
\text { heparin anti-coagulated plasma is loaded into the sample well } \\
\text { where it flows through the anti-ST2 antibody coated strip. Assay } \\
\text { buffer is added to the second well. The cassette is then inserted into } \\
\text { the ASPECT Reader for incubation, and ST2 is quantitatively } \\
\text { determined and reported by the reader. }\end{array}$ \\
\hline 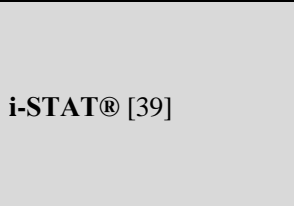 & Biosensor & $\begin{array}{l}\text { Hospital, Emergency department, } \\
\text { Critical care }\end{array}$ & - & $\begin{array}{l}\text { Each unique i-STAT System cartridge contains chemically sensitive } \\
\text { biosensors on a silicon chip that are configured for specific } \\
\text { analytes. } \\
\text { Quality checks of sample integrity, sensors, and fluidics are } \\
\text { automatic with each i-STAT cartridge run, providing confidence } \\
\text { and advanced performance. Sample size: } 95 \mu \mathrm{L} \text {. }\end{array}$ \\
\hline
\end{tabular}




\begin{tabular}{|c|c|c|c|c|}
\hline Brand name & Detection method & $\begin{array}{c}\text { Operating environment } \\
\text { (hospital, doctor's office, at } \\
\text { home) }\end{array}$ & Dimensions (mass, volume) & LOC description \\
\hline RapidPIA ${ }^{\circledR}[40]$ & $\begin{array}{l}\text { Reflected light intensity } \\
\text { method }\end{array}$ & Hospitals, doctor's office & $205 \times 275 \times 96 \mathrm{~mm}$ & Plastic cartridge containing the required antibodies and reagents. \\
\hline $\operatorname{Meritas}{ }^{\circledR}[41]$ & $\begin{array}{l}\text { Quantitative lateral flow } \\
\text { immunoassay that uses } \\
\text { fluorescence-based } \\
\text { measurement }\end{array}$ & Hospitals, doctor's office & $17,8 \times 27,4 \times 14,5 \mathrm{~cm}$ & $\begin{array}{c}\text { Plastic cartridge. } \\
\text { Lateral flow driven by capillary forces. } \\
\text { Filter to remove red blood cells, allowing only plasma to enter } \\
\text { The cartridge contains a microfluidic chip with a micropillar } \\
\text { surface, for a controlled and even flow. } \\
\text { The microfluidic chip has } 4 \text { zones: } \\
\text { Sample zone: the plasma makes contact with the assay chip. } \\
\text { Conjugate zone: with detection (fluorescent) antibodies in a } \\
\text { protective matrix. } \\
\text { Reaction zone: with immobilized capture antibodies. } \\
\text { Wicking zone: to control the flow and serve as a waste reservoir. }\end{array}$ \\
\hline Pathfast ${ }^{\circledR}[42]$ & $\begin{array}{l}\text { Immunoassay analyzer } \\
\text { (progressive } \\
\text { chemiluminescence) }\end{array}$ & $\begin{array}{l}\text { Laboratories, hospitals and } \\
\text { medical offices }\end{array}$ & $343(w)$ x 569 (d) x $475(\mathrm{~h}) \mathrm{mm}$ & $\begin{array}{l}\text { Proprietary Magtration technology ensures that small sample } \\
\text { Volumes can be analyzed with high accuracy and precision: } \\
\text { Magnetic particles / ALP-conjugated antibody / Chemiluminiscent } \\
\text { substrate / Sample diluent / Washing buffer. }\end{array}$ \\
\hline RAMP® ${ }^{\circledR}$ [43] & $\begin{array}{l}\text { Measurement of fluorescence } \\
\text { in various RAMP® } \\
\text { immunoassay applications }\end{array}$ & Hospitals, doctor's office, clinic & $\begin{array}{l}27 \mathrm{~cm} \text { wide } \times 25 \mathrm{~cm} \text { deep } \times 15 \mathrm{~cm} \\
\text { high }\end{array}$ & $\begin{array}{l}\text { Quantitative immunochromatographic test. Fluorescent-dyed } \\
\text { particles coated with anti-NT-proBNP antibodies bind to NT- } \\
\text { proBNP (if present in the sample). Single use test cartridge with } \\
\text { barcode defines lot specific calibration. Proprietary RAMP® buffer } \\
\text { enhances performance. }\end{array}$ \\
\hline Samsung LABGEO ${ }^{\circledR}[44]$ & Immunoessay & $\begin{array}{l}\text { Moving ambulances, during } \\
\text { emergencies }\end{array}$ & $\begin{array}{c}177 \mathrm{~mm}(\mathrm{H}) \times 177 \mathrm{~mm}(\mathrm{~W}) \times 330 \\
\mathrm{~mm}(\mathrm{D}), 2,4 \mathrm{~kg}\end{array}$ & $\begin{array}{l}\text { Microfluidic cartridge in the shape of a compact disc. Liquids move } \\
\text { by centrifugation on the spinning } \mathrm{CD} \text { inside the analyzer device. }\end{array}$ \\
\hline SHIONOSPOT ${ }^{\circledR}[45]$ & $\begin{array}{c}\text { Fluorescent } \\
\text { immunochromatographic }\end{array}$ & 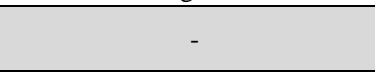 & $27(\mathrm{~W}) \mathrm{X} 25(\mathrm{D}) \mathrm{X} 15(\mathrm{H}) \mathrm{cm}, 2.1 \mathrm{~kg}$ & $\begin{array}{l}\text { It is a fluorescent immunochromatographic assay co-developed } \\
\text { with Response Biomedical using its RAMP technologies. }\end{array}$ \\
\hline Stratus ${ }^{\circledR}$ CS Analyzer [46] & $\begin{array}{l}\text { Dendrimer-enhanced radial } \\
\text { partition immunoassay }\end{array}$ & $\begin{array}{l}\text { Hospital, clinic, emergency } \\
\text { department }\end{array}$ & $\begin{array}{c}46 \mathrm{~cm}(\mathrm{H}) \times 71 \mathrm{~cm}(\mathrm{~W}) \times 58 \mathrm{~cm}(\mathrm{D}), \\
68 \mathrm{~kg}\end{array}$ & $\begin{array}{l}\text { Single and ready to use TestPaks Cartridges. No reconstitution. No } \\
\text { warming to room temperature. Reduction in reagent waste. } \\
\text { Examines heparinized whole blood samples. }\end{array}$ \\
\hline
\end{tabular}


Table IV: Measurable range, limit of detection (LoD), limit of quantification (LoQ), cut-off points and/or reference ranges of the commercially available POCT devices providing quantitative measurements of

\begin{tabular}{|c|c|c|c|c|c|}
\hline Brand name & Biomarker & Measurable range & LoD & LoQ & Cut off points / Reference range \\
\hline \multirow[b]{2}{*}{ Alere Triage ${ }^{\circledR}[36]$} & NT-proBNP & $20-35000 \mathrm{pg} / \mathrm{mL}$ & $20 \mathrm{pg} / \mathrm{mL}$ & $48 \mathrm{pg} / \mathrm{mL}$ & $\begin{array}{l}\text { Age }<75 \\
\text { NT-proBNP }>125 \mathrm{pg} / \mathrm{mL} \\
\text { Age }>=75 \\
\text { NT-proBNP }>450 \mathrm{pg} / \mathrm{mL} \text { (abnormal and suggestive of patients with CHF) }\end{array}$ \\
\hline & BNP & $5-5000 \mathrm{pg} / \mathrm{mL}$ & - & - & $\begin{array}{l}\text { - Cut off: } 100 \mathrm{pg} / \mathrm{mL} \\
\text { - } \mathrm{BNP}<=100 \mathrm{pg} / \mathrm{mL} \text { are representative of normal values in patients without } \\
\text { CHF. } \\
\text { - } \mathrm{BNP}>100 \mathrm{pg} / \mathrm{mL} \text { are considered abnormal and suggestive of patients with } \\
\text { CHF. } \\
\text { - BNP }>5000 \mathrm{pg} / \mathrm{mL} \text { are considered very high values for BNP and exceed the } \\
\text { upper limits of the BNP test. }\end{array}$ \\
\hline \multirow{5}{*}{$\begin{array}{l}\text { Roche Cobas h } 232 \\
\text { [37] }\end{array}$} & Troponin $\mathrm{T}$ & $50-2000 \mathrm{ng} / \mathrm{L}$ & - & - & $\begin{array}{l}\text { - }<50 \mathrm{ng} / \mathrm{L} \text { Acute Myocardial Infarction (AMI) not likely, but possible } \\
\text { - } 50-100 \mathrm{ng} / \mathrm{L} \text { AMI possible; initiate treatment accordingly (re-test) } \\
\text { - }>100 \mathrm{ng} / \mathrm{L} \text { AMI (very) likely; initiate treatment accordingly }\end{array}$ \\
\hline & NT-proBNP & $60-9000 \mathrm{pg} / \mathrm{mL}$ & - & - & $\begin{array}{l}\text { - Exclusion of non-acute } \mathrm{HF}<125 \mathrm{pg} / \mathrm{mL} \\
\text { - Exclusion of acute } \mathrm{HF}<300 \mathrm{pg} / \mathrm{mL} \\
\text { - Consideration of age-stratified cut-points for diagnosis: } \\
\text { - Age }<50 \rightarrow \text { NT-proBNP }>450 \mathrm{pg} / \mathrm{mL} \\
\text { - Age } 50-70 \rightarrow \text { NT-proBNP value }>900 \mathrm{pg} / \mathrm{mL} \\
\text { - Age }>75 \rightarrow \text { NT-proBNP value }>1800 \mathrm{pg} / \mathrm{mL} \\
\end{array}$ \\
\hline & D-dimer & $0.1-4.0 \mu \mathrm{g} / \mathrm{mL}$ & - & - & $0.5 \mu \mathrm{g} / \mathrm{mL}$ \\
\hline & Myoglobin & $30-700 \mathrm{ng} / \mathrm{mL}$ & - & - & Female: $7-64 \mathrm{ng} / \mathrm{mL}$ - Male: $16-76 \mathrm{ng} / \mathrm{mL}$ \\
\hline & CK-MB & $1.0-4.0 \mathrm{ng} / \mathrm{mL}$ & - & - & $\begin{array}{l}\text { Female: } 4 \mathrm{ng} / \mathrm{mL} \text { (at the } 99^{\text {th }} \text { percentile of a reference population) } \\
\text { Male: } 7 \mathrm{ng} / \mathrm{mL} \text { (at the } 99^{\text {th }} \text { percentile of a reference population) }\end{array}$ \\
\hline $\begin{array}{l}\text { ASPECT-PLUS } \\
\text { ST2 }[38]\end{array}$ & ST2 & $12.5-250 \mathrm{ng} / \mathrm{mL}$ & $12.5 \mathrm{ng} / \mathrm{mL}$ & $12.5 \mathrm{ng} / \mathrm{mL}$ & $\begin{array}{l}\text { - In self-declared healthy individuals, } \mathrm{ST} 2 \text { are } 15 \text { to } 25 \mathrm{ng} / \mathrm{mL} \text {. } \\
\text { - In patients diagnosed with ACS or HF and who have } \mathrm{ST} 2 \text { concentrations } \geq 35 \\
\mathrm{ng} / \mathrm{mL} \text { risk of adverse events such as hospitalization or mortality within one } \\
\text { (1) year is high. } \\
\text { - ST2 result, }<35 \mathrm{ng} / \mathrm{mL} \text {, in patients with HF or ACS may be used to classify } \\
\text { patients and individuals as low risk for adverse events such as } \\
\text { rehospitalization or death, clinically appropriate therapy should be pursued. }\end{array}$ \\
\hline \multirow{3}{*}{ i-STAT $®[39]$} & CTnI, & $0.0-50.0 \mathrm{ng} / \mathrm{mL}$ & - & - & $0.0-0.08 \mathrm{ng} / \mathrm{mL}$ (represents the $0-99 \%$ range of results) \\
\hline & CK-MB & $0.0-150.0 \mathrm{ng} / \mathrm{mL}$ & - & - & $0.0-3.5 \mathrm{ng} / \mathrm{mL}$ (represents the $95 \%$ range of results) \\
\hline & BNP & $15-5000 \mathrm{pg} / \mathrm{mL}$ & - & - & $<15.0-50.0 \mathrm{pg} / \mathrm{mL}$ (represents the $95 \%$ range of results) \\
\hline \multirow{6}{*}{ Pathfast ${ }^{\circledR}[40]$} & Troponin I, & $0.001-50 \mathrm{ng} / \mathrm{mL}$ & $0.02 \mathrm{ng} / \mathrm{mL}$ & - & - \\
\hline & NTproBNP & $15-30.000 \mathrm{pg} / \mathrm{mL}$ & $15 \mathrm{pg} / \mathrm{mL}$ & - & - \\
\hline & CK-MB & $2-500 \mathrm{ng} / \mathrm{mL}$ & $2.0 \mathrm{ng} / \mathrm{mL}$ & - & - \\
\hline & D-Dimer & $0.005-5 \mu \mathrm{g} / \mathrm{mL}$ FEU & $0.005 \mu \mathrm{g} / \mathrm{mL}$ & - & - \\
\hline & hsCRP & $0.05-30 \mathrm{mg} / \mathrm{L}$ & $0.05 \mathrm{mg} / \mathrm{L}$ & - & - \\
\hline & Myoglobin & $5-1000 \mathrm{ng} / \mathrm{mL}$ & $5.0 \mathrm{ng} / \mathrm{mL}$ & - & - \\
\hline \multirow{2}{*}{ RAMP® $[41]$} & NT-proBNP & $18-35000 \mathrm{ng} / \mathrm{L}$ & $\begin{array}{l}\mathrm{LLD}=18 \mathrm{ng} / \mathrm{L} \text { Results } \\
\text { exceeding } 35000 \mathrm{ng} / \mathrm{L} \text { are } \\
\text { reported as }>35000 \mathrm{ng} / \mathrm{L}\end{array}$ & - & $\begin{array}{l}125 \mathrm{ng} / \mathrm{L} \text { for }<75 \text { years } \\
450 \mathrm{ng} / \mathrm{L} \text { for }>75 \text { years }\end{array}$ \\
\hline & Troponin I & $0.03-32 \mathrm{ng} / \mathrm{mL}$ & $\begin{array}{l}\mathrm{LLD}=0.03 \mathrm{ng} / \mathrm{mL} \text { Results } \\
\text { exceeding } 32 \mathrm{ng} / \mathrm{mL} \text { are } \\
\text { reported as }>32 \mathrm{ng} / \mathrm{mL}\end{array}$ & - & 99th percentile: $0.10 \mathrm{ng} / \mathrm{mL}$ \\
\hline
\end{tabular}




\begin{tabular}{|c|c|c|c|c|c|}
\hline Brand name & Biomarker & Measurable range & LoD & LoQ & $\begin{array}{l}\text { Cut off points / Reference range } \\
\end{array}$ \\
\hline & D-Dimer & $100-5000 \mathrm{ng} / \mathrm{mL}$ FEU & $<100 \mathrm{ng} / \mathrm{mL}$ FEU & - & 99th percentile: $386 \mathrm{ng} / \mathrm{mL}$ FEU \\
\hline \multirow{5}{*}{$\begin{array}{l}\text { Samsung LABGEO }{ }^{\circledR} \\
{[42]}\end{array}$} & CK-MB & $2-60 \mathrm{ng} / \mathrm{mL}$ & - & - & Upper reference limit: $8.58 \mathrm{ng} / \mathrm{mL}$ \\
\hline & Myoglobin & $30-500 \mathrm{ng} / \mathrm{mL}$ & - & - & Upper reference limit: $99.84 \mathrm{ng} / \mathrm{mL}$ \\
\hline & D-Dimer & $100-4000 \mathrm{ng} / \mathrm{mL}$ FEU & - & - & Upper reference limit: $446.8 \mathrm{ng} / \mathrm{mL}$ FEU \\
\hline & Troponin I & $0.05-30 \mathrm{ng} / \mathrm{mL}$ & - & - & Upper reference limit: $0.01 \mathrm{ng} / \mathrm{mL}(99 \%)$ \\
\hline & NT-proBNP & $30-5000 \mathrm{pg} / \mathrm{mL}$ & - & - & $\begin{array}{r}\text { Upper reference limit: age }<75125 \mathrm{pg} / \mathrm{mL} \\
\text { age }>=75450 \mathrm{pg} / \mathrm{mL}\end{array}$ \\
\hline $\begin{array}{l}\text { SHIONOSPOT }{ }^{\circledR} \\
{[45]}\end{array}$ & $\mathrm{BNP}$ & $6-2000 \mathrm{pg} / \mathrm{mL}$ & - & - & ( \\
\hline \multirow{6}{*}{$\begin{array}{l}\text { Stratus }{ }^{\circledR} \text { CS } \\
\text { Analyzer }[46]\end{array}$} & Troponin I & $0.03-50 \mu \mathrm{g} / \mathrm{L}$ & $<0.03 \mu \mathrm{g} / \mathrm{L}$ & - & - \\
\hline & D-Dimer & $0.3-150 \mu \mathrm{g} / \mathrm{L}$ FEU & $0.3 \mu \mathrm{g} / \mathrm{L}$ FEU & - & - \\
\hline & NT-proBNP & $15-20.000 \mathrm{pg} / \mathrm{mL}$ & $15 \mathrm{pg} / \mathrm{mL}$ & - & - \\
\hline & hsCRP & $0.1-50 \mathrm{mg} / \mathrm{L}$ & $<=0.1 \mathrm{mg} / \mathrm{L}$ & - & - \\
\hline & CK-MB & $0.3-150 \mu \mathrm{g} / \mathrm{L}$ & $0.3 \mu \mathrm{g} / \mathrm{L}$ & - & - \\
\hline & Myoglobin & $1-900 \mu \mathrm{g} / \mathrm{L}$ & $1 \mu \mathrm{g} / \mathrm{L}$ & - & - \\
\hline
\end{tabular}


Table V: Biomarker(s) related with cardiovascular diseases/conditions.

\begin{tabular}{l||l}
\hline \hline \multicolumn{1}{c|}{ Cardiovascular disease/conditions } & NT-proBNP \\
\hline Heart failure & TnI, CK-MB, and MYO \\
\hline Myocardial necrosis & CRP, MMP-9, MPO \\
\hline Inflammation, tissue injury and remodeling & CRP, IL-6, IL-1 $\beta$, MPO, sCD40L, TNF- $\alpha$, Adip, sICAM-1, MMP-9 \\
\hline Acute myocardial infarction (AMI) & MMP-8, lysozyme \\
\hline Hypertension & LTB4 and PGE2 \\
\hline Arterial stiffness & $\begin{array}{l}\text { CRP, MMP-9, IL-1beta, sICAM-1, adiponectin, MCP-1, Gro-alpha, E- } \\
\text { selectin, IL-18, ENA-78, sVCAM-1, MPO, MYO, CK-MB, TnI, BNP, } \\
\text { sCD40-L TNF- } \alpha, \text { Fractalkine, IL-6, Adiponectin }\end{array}$ \\
\hline AMI patients within 48 $h$ of chest pain onset & cTnI \\
\hline 12 and 24 h of onset of Myocardial Infarction & MMP-8 \\
\hline Patients who had under gone heart surgery & CRP, MMP-9 \\
\hline $\begin{array}{l}\text { Intima-media thickness } \\
\text { Pre-existing CVD diseased patients who underwent an } \\
\text { invasive cardiac procedure }\end{array}$ & $\begin{array}{l}\text { CRP, TNF- } \alpha, \text { sCD40L, IL-1 } \beta, \text { IL-6, adiponectin, MMP-9, MPO, sICAM- } \\
1\end{array}$ \\
\hline \hline
\end{tabular}




\section{List of Tables}

Table I: Blood biomarkers related to HF.

Table II: Commercially available POCT devices providing quantitative measurements of cardiovascular biomarker(s) by analyzing blood samples - PART A.

Table III: Commercially available POCT devices providing quantitative measurements of cardiovascular biomarker(s) by analyzing blood samples - PART B.

Table IV: Measurable range, limit of detection (LoD), limit of quantification (LoQ), cut-off points and/or reference ranges of the commercially available POCT devices providing quantitative measurements of cardiovascular biomarker(s) by analyzing blood samples.

Table V: Biomarker(s) related with cardiovascular diseases/conditions.

APPENDIX 1: Literature Review Search Strategy

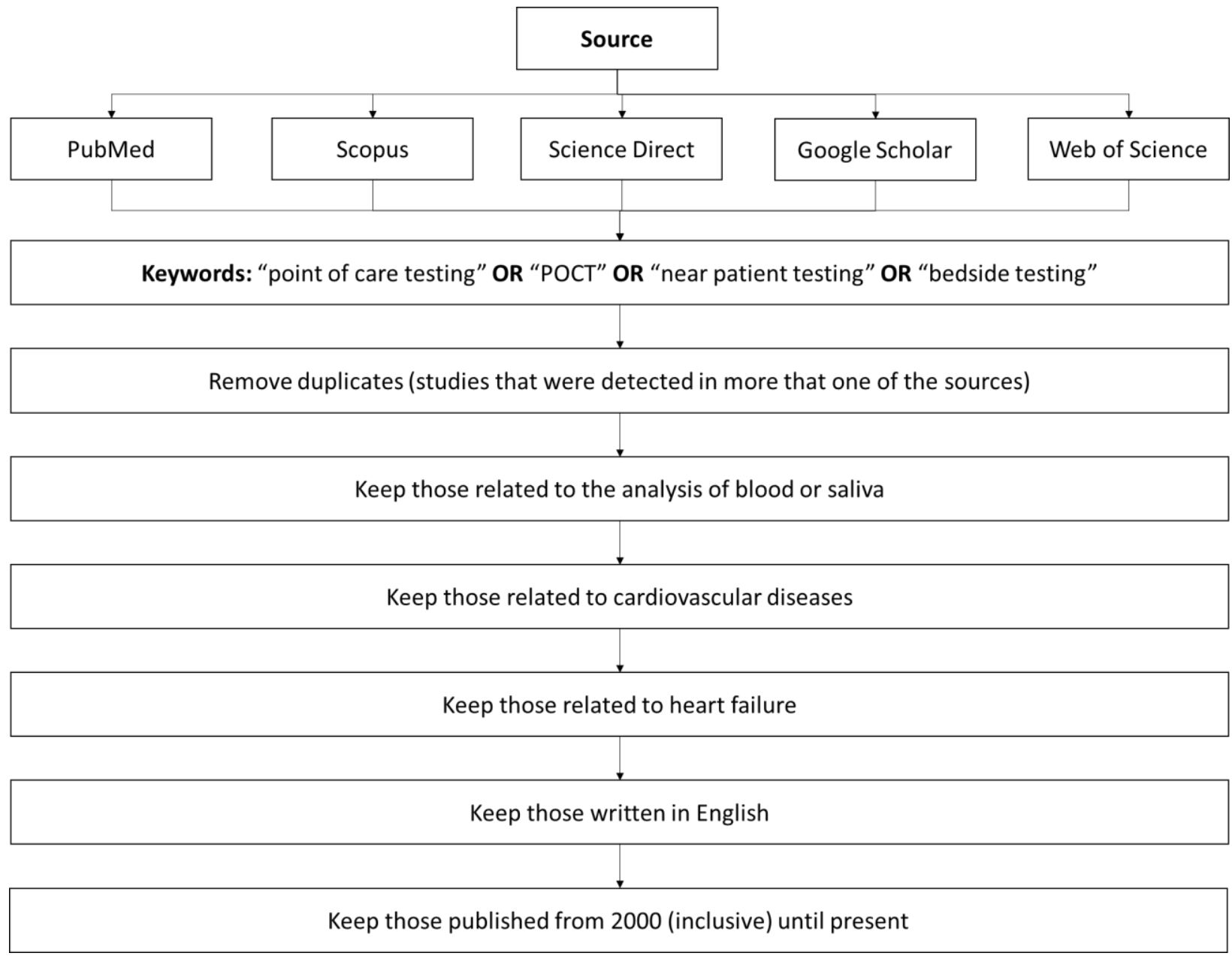

